NISTIR 8393

\title{
Sensitivity to X-Ray Computed Tomography Instrument Geometry Errors as a Function of Rotation Stage Position, Detector Position, and Detector Size
}

\author{
Bala Muralikrishnan \\ Prashanth Jaganmohan \\ Meghan Shilling \\ Ed Morse
}

This publication is available free of charge from: https://doi.org/10.6028/NIST.IR.8393

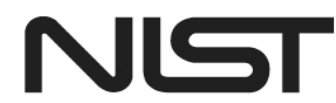

National Institute of Standards and Technology U.S. Department of Commerce 


\title{
Sensitivity to X-Ray Computed Tomography Instrument Geometry Errors as a Function of Rotation Stage Position, Detector Position, and Detector Size
}

\author{
Bala Muralikrishnan \\ Meghan Shilling
}

Sensor Science Division, Physical Measurement Laboratory, NIST

Gaithersburg MD 20899

Prashanth Jaganmohan

Ed Morse

Center for Precision Metrology, University of North Carolina at Charlotte

Charlotte NC 28223

This publication is available free of charge from:

https://doi.org/10.6028/NIST.IR.8393

September 2021

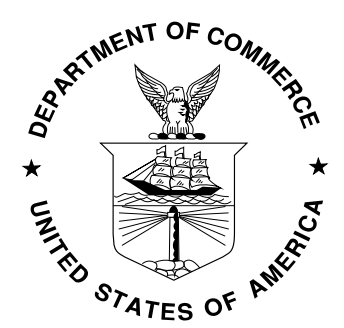

U.S. Department of Commerce Gina M. Raimondo, Secretary

National Institute of Standards and Technology James K. Olthoff, Performing the Non-Exclusive Functions and Duties of the Under Secretary of Commerce for Standards and Technology \& Director, National Institute of Standards and Technology 
Certain commercial entities, equipment, or materials may be identified in this document in order to describe an experimental procedure or concept adequately. Such identification is not intended to imply recommendation or endorsement by the National Institute of Standards and Technology, nor is it intended to imply that the entities, materials, or equipment are necessarily the best available for the purpose.

National Institute of Standards and Technology Interagency or Internal Report 8393

Natl. Inst. Stand. Technol. Interag. Intern. Rep. 8393, 31 pages (September 2021)

This publication is available free of charge from: https://doi.org/10.6028/NIST.IR.8393 


\begin{abstract}
In two prior National Institute of Standards and Technology (NIST) Journal of Research publications (Parts I and II) [1-2], we presented test procedures to detect instrument geometry errors in industrial cone beam X-ray computed tomography (XCT) systems. These test procedures were based on simulations performed at one position of the measurement volume (one geometrical configuration of the instrument), i.e., for fixed locations of the rotation stage (400 $\mathrm{mm}$ from the source) and the detector (1177 $\mathrm{mm}$ from the source). In a subsequent NIST Journal of Research publication (Part III) [3], we reported results from simulations performed at various combinations of the rotation stage and detector distances from the source. Because of the large number of simulations, we abstracted the information and reported key observations only. This internal report presents the underlying data generated from the simulations performed for the Part III publication and may therefore be considered an addendum to that publication.
\end{abstract}

\title{
Key words
}

Cone-beam; distance error; documentary standards; form error; geometry errors; performance evaluation; sensitivity analysis; single-point ray tracing method; X-ray computed tomography. 


\section{Table of Contents}

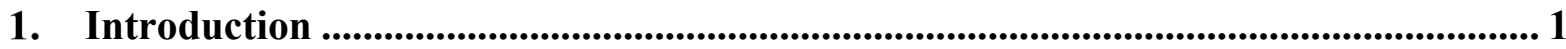

2. Reference object, error sources, simulation procedure, and interpreting the charts 2

2.1. Reference object and coordinate system ...................................................... 2

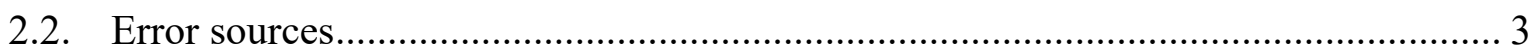

2.3. Simulation procedure ................................................................................... 4

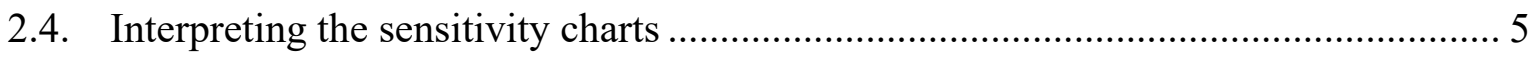

3. Detector geometry errors and rotation stage $Z$ location error ...............................5 5

4. Rotation stage error motions ......................................................................... 10

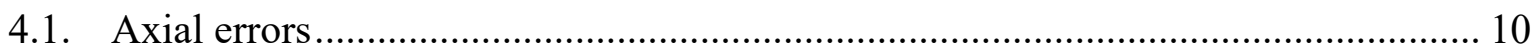

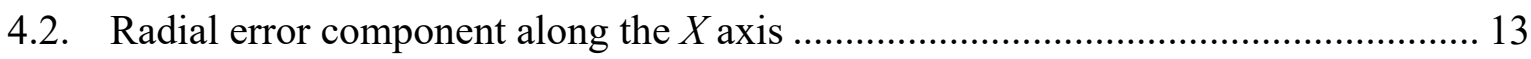

4.3. Radial error component along the $Z$ axis...................................................... 15

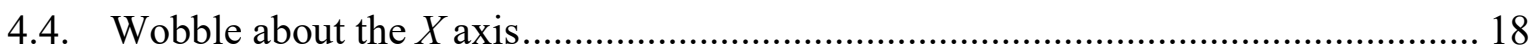

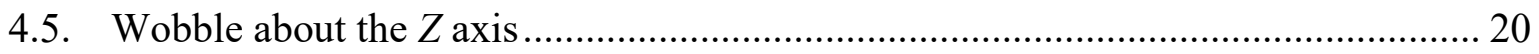

4.6. Scale (angular indexing) errors in the rotation stage encoder .............................. 22

5. Summary and conclusions .................................................................................. 25

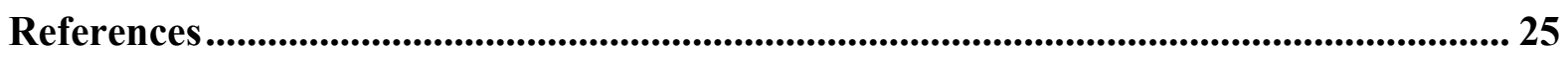




\section{Introduction}

The American Society of Mechanical Engineers (ASME) published a documentary standard for performance evaluation of X-ray computed tomography (XCT) systems in early 2021. This standard, the ASME B89.4.23 [4], prescribes test procedures to evaluate XCT systems used for dimensional measurements. Another performance evaluation documentary standards activity is currently ongoing within the International Organization for Standardization (ISO) Technical Committee (TC) 213 [5]. A key aspect in the development of such standards is in identifying test procedures that are sensitive to all known systematic sources of error. This is exceedingly challenging for XCT systems because of the large number and the complexity of the error sources.

In two prior National Institute of Standards and Technology (NIST) Journal of Research publications (Parts I and II $[1,2]$ ), we focused on one error source, geometry errors in conebeam XCT systems, and its effect on dimensional measurements. Geometry errors include errors associated with the position and pose of the detector, position of the rotation stage, and error motions of the rotation stage (such as axial, radial, wobble, and scale (angular indexing) errors). We have utilized the model of a multi-sphere reference object developed by Ferrucci et al. [6-8] and determined optimal placement of spheres in the measurement volume to effectively detect the geometry errors in XCT systems. That is, for each of the geometry error sources discussed in Parts I and II, we determined the pair of spheres in the measurement volume that produced the largest center-to-center distance error. We also identified the sphere that produced the largest form error. We then calculated the distance error and form error sensitivity as the ratio of the distance error and form error, respectively, to the magnitude of the imposed geometry error in the simulation. The key contributions of Parts I and II were these sensitivity coefficients for each of the different geometry error sources in XCT systems. However, those results were limited to simulations performed at one location in the machine volume, i.e., rotation stage position of $400 \mathrm{~mm}$ and detector position of $1177 \mathrm{~mm}$, both with respect to the X-ray source, and for a measurement volume size based on a square detector of size $190 \mathrm{~mm}$.

We then expanded on the previous work and performed such simulations for various combinations of detector and rotation stage distances from the source. Given the large number of simulations performed, we abstracted the information and presented key findings in Part III [3]. In this internal report, we present the underlying sensitivity data generated from those simulations. Therefore, this report may be considered an addendum to Part III. Throughout this report, we present two plots for each geometry error source - distance error sensitivity and form error sensitivity. These plots are generated for different combinations of rotation stage and detector positions, and different detector sizes. The distance error sensitivity plot shows the largest anticipated distance error within the measurement volume for unit magnitude of a geometry error source. Likewise, the form error sensitivity plot shows the largest anticipated form error within the measurement volume for unit magnitude of a geometry error source. These plots help the user determine optimal placement of a reference object (such as a cylinder with spheres mounted on the surface whose center distances are previously calibrated) to test the performance of XCT systems and determine whether they meet the manufacturer specifications. 


\section{Reference object, error sources, simulation procedure, and interpreting the charts}

\subsection{Reference object and coordinate system}

The reference object we considered in Parts I and II consisted of 125 spheres, $3 \mathrm{~mm}$ nominal diameter, equally distributed in five horizontal $(X Z)$ planes located at the following $Y$ positions: $-25 \mathrm{~mm},-12.5 \mathrm{~mm}, 0 \mathrm{~mm}, 12.5 \mathrm{~mm}$, and $25 \mathrm{~mm}$, as shown in Fig. 1(a). At each of these five $Y$ positions, one sphere was located on the cylindrical axis, eight spheres were equally spaced on a circle of $25 \mathrm{~mm}$ diameter, and 16 spheres were equally spaced on a circle of $50 \mathrm{~mm}$ diameter (Fig. 1(b)). The simulations were performed with the rotation stage located at $Z=-400 \mathrm{~mm}$ from the source. The outer ring diameter of $50 \mathrm{~mm}$ and cylinder height of $50 \mathrm{~mm}$ were chosen to fill the square detector with $190 \mathrm{~mm}$ side length and for a detector located at $Z=-1177 \mathrm{~mm}$. The reference object was located on the rotation stage in such a manner that the axis of the cylinder was coincident with the axis of rotation and the local $X$ and $Z$ axes of the object were parallel to the global $X$ and $Z$ axes at the first angular position of the rotation stage.

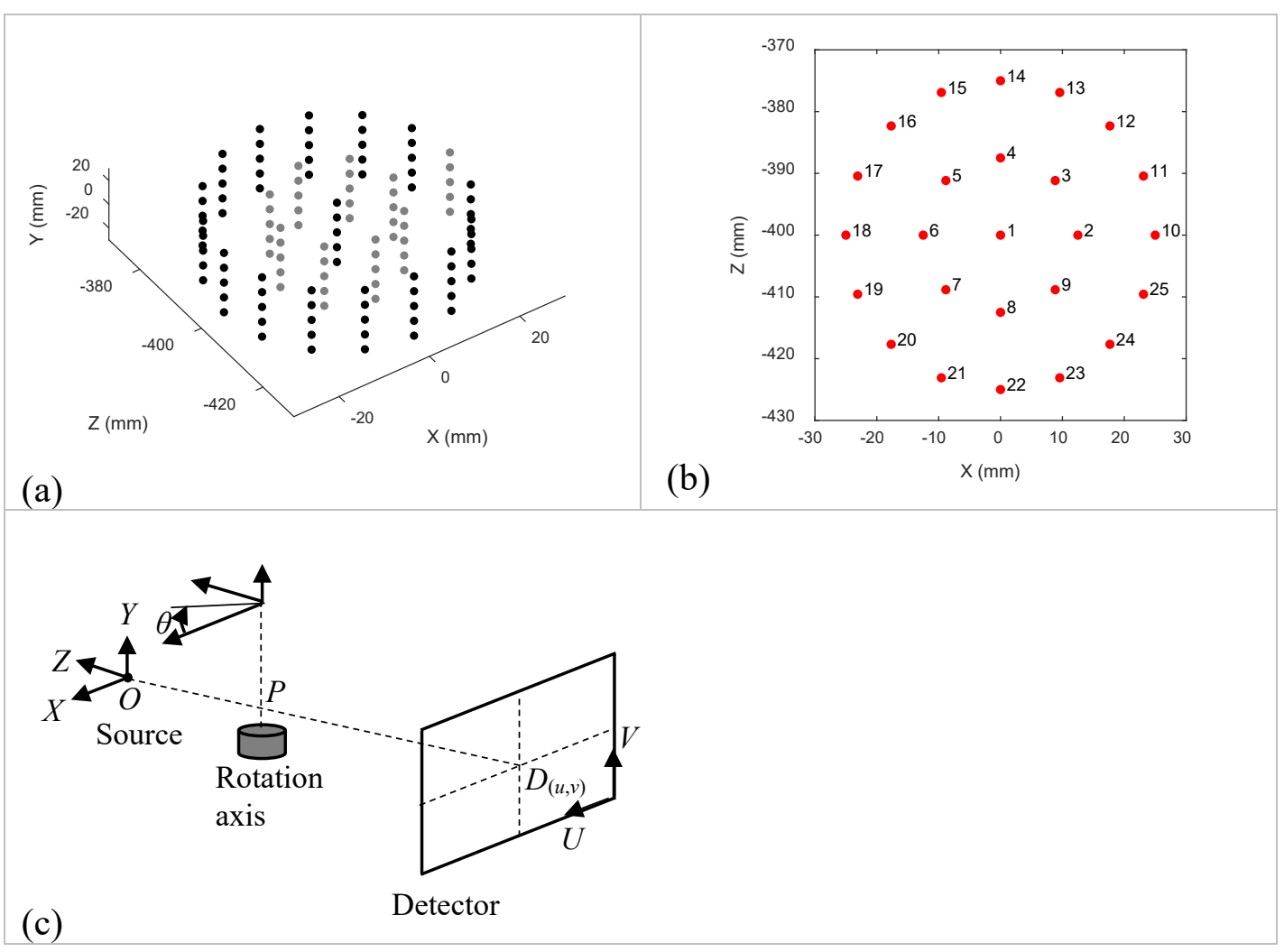

Fig. 1. (a) Three-dimensional view of the reference object comprising 125 spheres. (b) Top view of the same object with sphere numbering shown for the spheres in lowest horizontal plane $(Y=-25 \mathrm{~mm})$. Note that the source was located at $Z=0 \mathrm{~mm}$ and the detector was located at $Z=-1177 \mathrm{~mm}$. (c) Coordinate system definition showing the global coordinate system with origin located at $O$.

The spheres were numbered as follows. Spheres 1 to 25 were located at the $Y=-25 \mathrm{~mm}$ plane, spheres 26 to 50 were located at the $Y=-12.5 \mathrm{~mm}$ plane, spheres 51 to 75 were located at the $Y=0 \mathrm{~mm}$ plane, spheres 76 to 100 were located at the $Y=12.5 \mathrm{~mm}$ plane, and 
spheres 101 to 125 were located at the $Y=25 \mathrm{~mm}$ plane. The first sphere in each of the five horizontal planes was located on the cylindrical axis, the next eight spheres were located on the inner circle, and the remaining 16 spheres were located on the outer circle. In each circle, the numbering starts on the $+X$ axis and increases towards the $+Z$ axis. For example, sphere 2 was located at $(12.5,-25,-400) \mathrm{mm}$ and sphere 4 was located at $(0,-25,-400+12.5) \mathrm{mm}$. The numbering scheme is important in Secs. 3 and 4 as we identify the pair of spheres that produce the largest distance error or the sphere that produce the largest form error, for a given geometric error source.

Figure 1(c) shows the coordinate system employed for the simulations in Parts I and II. The origin was located at the source $O$. Point $P$ was located on the axis of rotation so that the line $O P$ was orthogonal to the rotation axis. This line ideally intersects the center of the detector at point $D$. The global $Z$ axis was coincident with the line $O P$. The global $X$ and $Y$ axes were as shown in Fig. 1(c).

For Part III of the series of publications, we performed the sensitivity analysis at different simulated positions of the rotation stage and detector, and for different detector sizes, so for each combination, we scaled the reference object to almost fill the detector as described here. Let $d$ and $D$ be the distances of the rotation stage and the detector from the source, respectively, and let $R$ be the radius of the outer ring of spheres in the reference object. Then, the radius of the inner ring of spheres was $R / 2$ and the five $Y$ positions were located at $-2 R$, $-R, 0, R$, and $2 R$. Thus, the height of the reference object, determined as the distance along the $Y$ axis from the center of a sphere in lowest $Y$ plane to the center of a sphere in the highest $Y$ plane, was $2 R$. The radius of the sphere, $r$, was set to be $10 \%$ of the outer ring radius $R$ of the reference object, i.e., $r=0.1 R$. This allowed the sphere to project over a relatively constant area of the detector regardless of the positions of the rotation stage and the detector. Let $s$ be the size of the square detector. Allowing the reference object to fill $98 \%$ of the detector, from simple trigonometry we determined the radius of the outer ring $R$ as

$$
R=\frac{0.98 d s}{(2.2 D+0.98 s)}
$$

We considered rotation stage positions $d$ from $200 \mathrm{~mm}$ through $1100 \mathrm{~mm}$ in steps of $100 \mathrm{~mm}$ and detector positions $D$ from $d+100 \mathrm{~mm}$ through $1200 \mathrm{~mm}$ in steps of $100 \mathrm{~mm}$. We considered three sizes $s$ for the square detector, $150 \mathrm{~mm}, 200 \mathrm{~mm}$, and $250 \mathrm{~mm}$. Note that a larger detector size results in a larger measurement volume, so the reference object is correspondingly larger. The data generated from these simulations are presented in this report.

\subsection{Error sources}

The detector errors include the three location errors along each Cartesian axis of the instrument coordinate frame and three angular errors about the same axes. The rotation stage errors include a $Z$ location error, and the error motions of the stage itself. These stage error motions, including axial, radial, wobble (often referred to as tilt errors in documentary standards), and encoder scale (indexing angle) errors, are all assumed to have harmonic components and therefore are represented as sine and cosine functions of the nominal rotation stage indexing angle $\theta$, i.e., of the form $a \sin (n \theta)$ and $a \cos (n \theta))$, where $a$ represents the amplitude or magnitude of the error and $n$ is the order of the harmonic. The $X$ and $Y$ positioning errors of the stage have no physical 
meaning due to the way the coordinate system is defined. Table 1 presents a list of the error sources considered.

For the simulations in Parts I, II, and III, we considered harmonics of orders one through ten for the rotation stage error motions. Thus, there were six detector errors, one rotation stage position error (along $Z$ ), and 120 error sources associated with the sample stage motion, for a total of 127 errors. In Sec. 4 of this report, we only present plots for the first four orders for each of the rotation stage error motions, since low orders are generally the dominant error sources in rotation stages.

For any given geometry error parameter described in Table 1, we have performed (but not reported here) simulations for different magnitudes of the introduced geometry error to ensure that the center-to-center distance error and sphere form error have a linear relationship with the introduced geometry error.

Table 1. XCT instrument geometry errors.

\begin{tabular}{|c|c|}
\hline $\begin{array}{c}\text { Detector geometry errors and rotation } \\
\text { stage } Z \text { location error }\end{array}$ & Rotation stage error motions \\
\hline $\begin{array}{ll}\text { - } & \text { Detector } X \text { location error } \\
\text { - } & \text { Detector } Y \text { location error } \\
\text { - } & \text { Detector } Z \text { location error } \\
\text { - } & \text { Detector } X \text { rotation error } \\
\text { - } & \text { Detector } Y \text { rotation error } \\
\text { - } & \text { Detector } Z \text { rotation error } \\
\text { - } & \text { Rotation stage } Z \text { location error }\end{array}$ & $\begin{array}{ll}\text { - } & \text { Axial error (along } Y \text { axis) } \\
\text { - } & \text { Radial error along } X \text { axis } \\
\text { - } & \text { Radial error along } Z \text { axis } \\
\text { - } & \text { Wobble error about } X \\
\text { - } & \text { Wobble error about } Z \\
\text { - } & \text { Scale (angular indexing) errors in the } \\
& \text { indexing angle }\end{array}$ \\
\hline $\begin{array}{l}\text { Each of the above term is a scalar, thus there } \\
\text { are seven error sources in all }\end{array}$ & $\begin{array}{l}\text { There are } 20 \text { components ( } 10 \text { cosine and } \\
10 \text { sine orders) considered in this study for } \\
\text { each of the six terms listed above (axial, } \\
\text { radial } X \text {, radial } Z \text {, wobble } X \text {, wobble } Z \text {, and } \\
\text { scale), for a total of } 120 \text { error sources. } \\
\text { However, plots in Sec. } 4 \text { are shown for } \\
\text { first four cosine (or sine) orders only, thus } \\
\text { for a total of } 24 \text { error sources. }\end{array}$ \\
\hline
\end{tabular}

Note: See Ref. [3] for magnitude of the imposed geometry error in the simulations.

\subsection{Simulation procedure}

The simulations were performed separately for each of the different geometry error sources identified in Parts I and II. We describe the procedure here using the detector $X$ location error as an example.

We set the detector $X$ location error to be a constant amount, say, $0.1 \mathrm{~mm}$. We set with the detector size $s$ as $150 \mathrm{~mm}$. We commenced the simulations with the rotation stage position $d$ and detector position $D$ equal to $200 \mathrm{~mm}$ and $300 \mathrm{~mm}$, respectively. We calculated the outer ring radius $R$ of the reference object and the radius $r$ of the individual spheres in that object and determined the center locations of each of the 125 spheres. We then used the single-point 
ray tracing method (described in [1-2]) to determine the sphere centers of the reconstructed object in the presence of the detector $X$ location error of $0.1 \mathrm{~mm}$. We calculated sphere center-to-center distance errors for all pairs of spheres and the form error for each of the 125 spheres. We recorded the largest distance error and the largest form error. We calculated the ratio of these errors to the imposed detector $X$ location error of $0.1 \mathrm{~mm}$. These ratios are the sensitivity of the distance error and the sensitivity of the form error to detector $X$ location error. We repeated this process for other detector sizes, rotation stage positions, and detector positions.

We note that acquiring such a large set of results was only possible because of the computational efficiency provided by the single-point ray tracing method, which we described in Part I. We have validated the single-point ray tracing method against the radiograph-based method for selected positions, see Parts I and II for validation information. We also note that the actual magnitude of the form error is somewhat influenced by the implementation of the single-point ray tracing method when generating the form error point cloud. We have noticed differences in form error of about $10 \%$ between different implementations, especially between algorithms that retain and algorithms that discard data near the poles of the sphere.

\subsection{Interpreting the sensitivity charts}

The sensitivity charts shown in subsequent sections may be interpreted as follows. The ordinate represents the sensitivity, which is either in units of $\mathrm{mm} / \mathrm{mm}$ or $\mathrm{mm} /$ degree. Each block of data, delineated by solid vertical lines in the charts, corresponds to a certain rotation stage position $d$. Within each block, the detector position $D$ (shown by the abscissa) ranges from $d+100 \mathrm{~mm}$ to $1200 \mathrm{~mm}$. There are three curves in each block, corresponding to different detector sizes. For example, the first block comprising 10 data points per curve corresponds to rotation stage position $d$ of $200 \mathrm{~mm}$. Within this block, the 10 detector positions range from $300 \mathrm{~mm}$ through $1200 \mathrm{~mm}$ in increments of $100 \mathrm{~mm}$. In the charts, we highlight the rotation stage position of $400 \mathrm{~mm}$ and detector position of $1177 \mathrm{~mm}$ (shown as a dashed vertical line), as a reference for the work reported earlier in Parts I and II.

The data presented in the distance error sensitivity charts correspond to one or more specific pair of spheres in the reference object. Likewise, the data shown in the form error sensitivity charts correspond to one or more specific spheres in the reference object. We identify these spheres in Secs. 3 and 4. In Part III, we defined two positions in the measurement volume where we observed the maximum sensitivity - the so called "near position" and the "far position". We define those terms here as we will use them extensively in Secs. 3 and 4:

- Near position: The rotation stage is closest to the source and the detector is closest to the rotation stage, thus $d=200 \mathrm{~mm}$ and $D=300 \mathrm{~mm}$.

- Far position: The detector is farthest from the source and the rotation stage is closest to the detector, thus, $d=1100 \mathrm{~mm}$ and $D=1200 \mathrm{~mm}$.

Note that both the near and far positions are low-magnification positions, i.e., with the detector as close as possible to the rotation stage.

\section{Detector geometry errors and rotation stage $Z$ location error}

In this section, we present the distance and form error sensitivities to the six detector geometry errors described in Part I and the rotation stage $Z$ location error described in Part II. Fig. 2 shows the distance and form error sensitivities to detector $X$ location error, Fig. 3 
shows the sensitivities to detector $Y$ location error, Fig. 4 shows the sensitivities to detector $Z$ location error, Fig. 5 shows the distance error sensitivity to detector $X$ rotation error (form error sensitivity not shown because it is less than $0.005 \mathrm{~mm} /{ }^{\circ}$ and therefore negligible), Fig. 6 shows the sensitivities to detector $Y$ rotation error, Fig. 7 shows the sensitivities to detector $Z$ rotation error, and Fig. 8 shows the distance error sensitivity to rotation stage $Z$ location error (form error sensitivity not shown because it is negligible).

Tables 2 and 3 present the maximum sensitivities, the position ('near' or 'far') where they occur, and the sphere numbers that produce that sensitivity. Note that there may be several pairs of spheres that produce the same distance error sensitivity, some example pairs are identified in Table 2. Note also that there may be several spheres that produce the same form error sensitivity, one or more such spheres are identified in Table 3. Maximum sensitivities shown in the tables are for detector size $s=250 \mathrm{~mm}$ and for the position shown ('near' or 'far'). Two error sources (detector $X$ rotation and rotation stage $Z$ location errors) are not sensitive to form error, so they can only be detected from distance errors.

Table 2. Distance error sensitivity to detector geometry errors and rotation stage $Z$ location error.

\begin{tabular}{|l|l|l|l|}
\hline Error source & $\begin{array}{l}\text { Maximum } \\
\text { sensitivity }\end{array}$ & Position & Corresponding sphere pairs \\
\hline Detector $X$ location & $0.022 \mathrm{~mm} / \mathrm{mm}$ & Near & $(10,73),(14,67),(18,71),(22,75)$ \\
\hline Detector $Y$ location & $0.084 \mathrm{~mm} / \mathrm{mm}$ & Near & $(10,18),(14,22),(110,118),(114,122)$ \\
\hline Detector $Z$ location & $0.477 \mathrm{~mm} / \mathrm{mm}$ & Near & $(10,118),(14,122),(18,110),(22,114)$ \\
\hline Detector $X$ rotation & $0.512 \mathrm{~mm} /{ }^{\circ}$ & Near & $(10,18),(14,22),(110,118),(114,122)$ \\
\hline Detector $Y$ rotation & $0.043 \mathrm{~mm} /{ }^{\circ}$ & Near & $(10,64),(14,68),(64,110),(68,114)$ \\
\hline Detector $Z$ rotation & $0.008 \mathrm{~mm} /{ }^{\circ}$ & Far & $(10,118),(14,122),(18,110),(22,114)$ \\
\hline $\begin{array}{l}\text { Rotation stage } Z \\
\text { location }\end{array}$ & $0.766 \mathrm{~mm} / \mathrm{mm}$ & Near & $(10,118),(14,122),(18,110),(22,114)$ \\
\hline
\end{tabular}

Table 3. Form error sensitivity to detector geometry errors and rotation stage $Z$ location error.

\begin{tabular}{|l|l|l|l|}
\hline Error source & $\begin{array}{l}\text { Maximum } \\
\text { sensitivity }\end{array}$ & Position & Corresponding spheres \\
\hline Detector $X$ location & $0.88 \mathrm{~mm} / \mathrm{mm}$ & Far & $10,14,18,22$ \\
\hline Detector $Y$ location & $0.30 \mathrm{~mm} / \mathrm{mm}$ & Near & $10,14,18,22$ \\
\hline Detector $Z$ location & $0.09 \mathrm{~mm} / \mathrm{mm}$ & Near & $10,14,18,22$ \\
\hline Detector $X$ rotation & 0 & - & - \\
\hline Detector $Y$ rotation & $0.45 \mathrm{~mm} /{ }^{\circ}$ & Near & $10,14,18,22$ \\
\hline Detector $Z$ rotation & $2.52 \mathrm{~mm} /{ }^{\circ}$ & Far & $10,14,18,22$ \\
\hline $\begin{array}{l}\text { Rotation stage } Z \\
\text { location }\end{array}$ & 0 & - & - \\
\hline
\end{tabular}



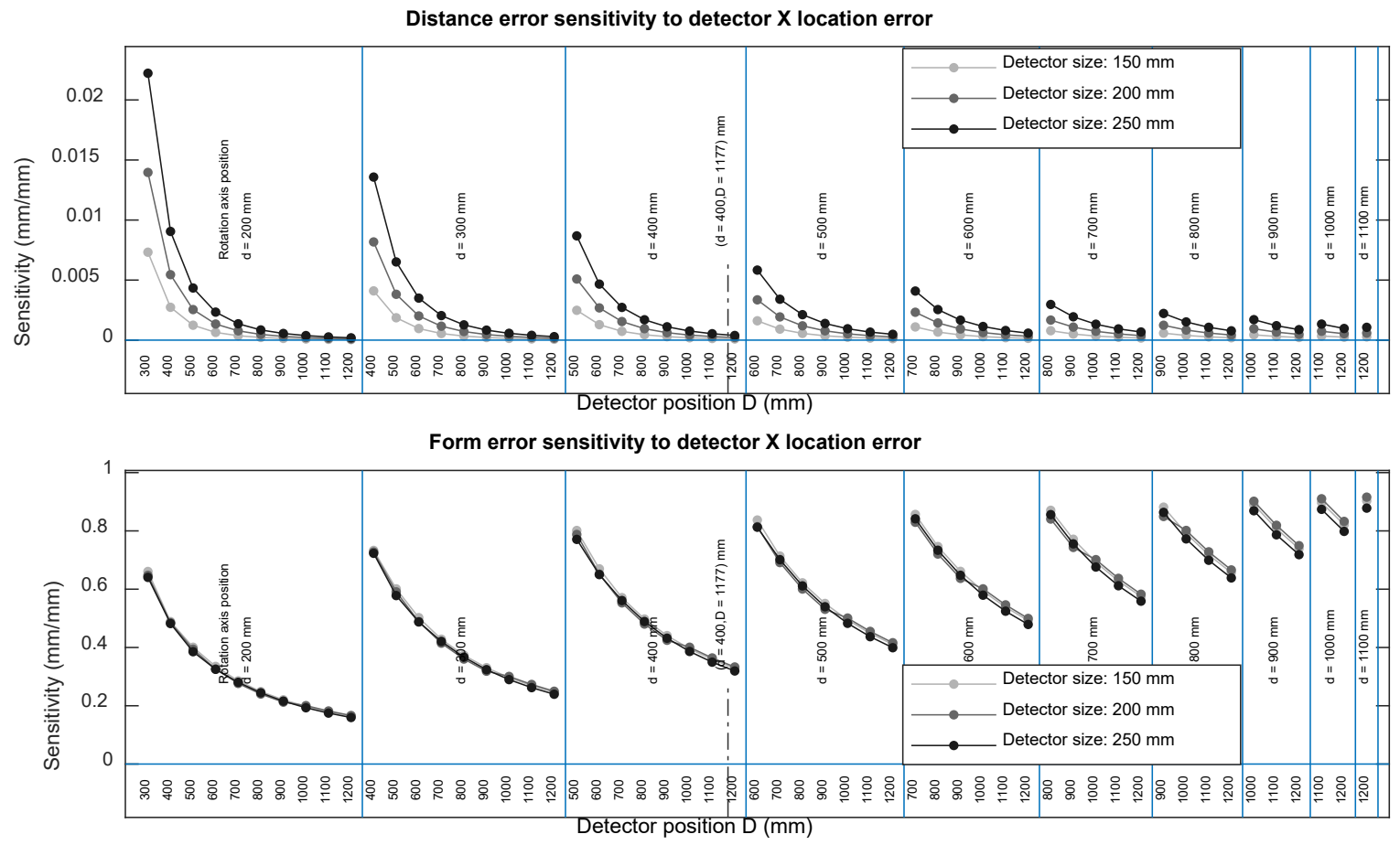

Fig. 2. Distance (top) and form (bottom) error sensitivity to detector $X$ location error.
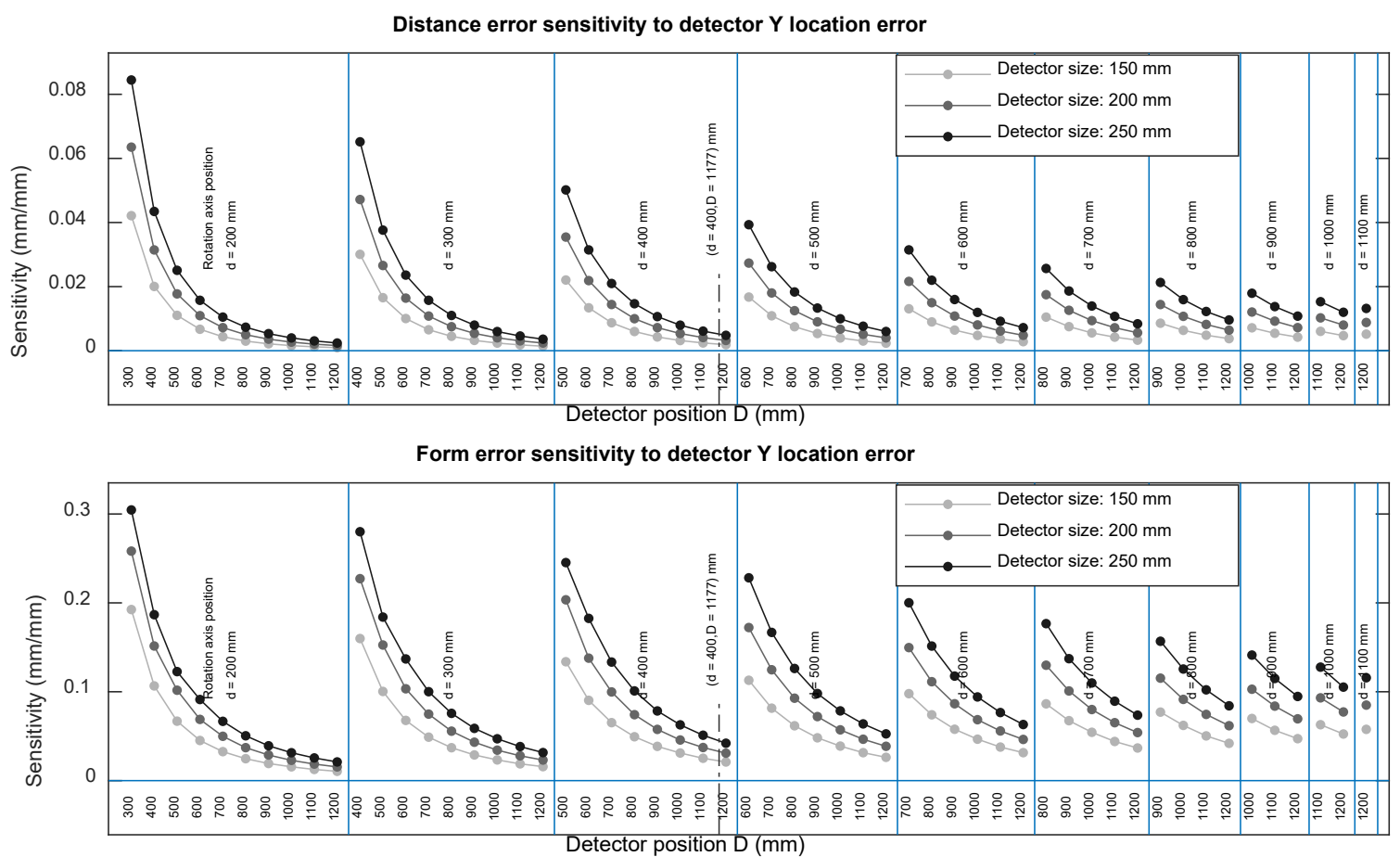

Fig. 3. Distance (top) and form (bottom) error sensitivity to detector $Y$ location error. 

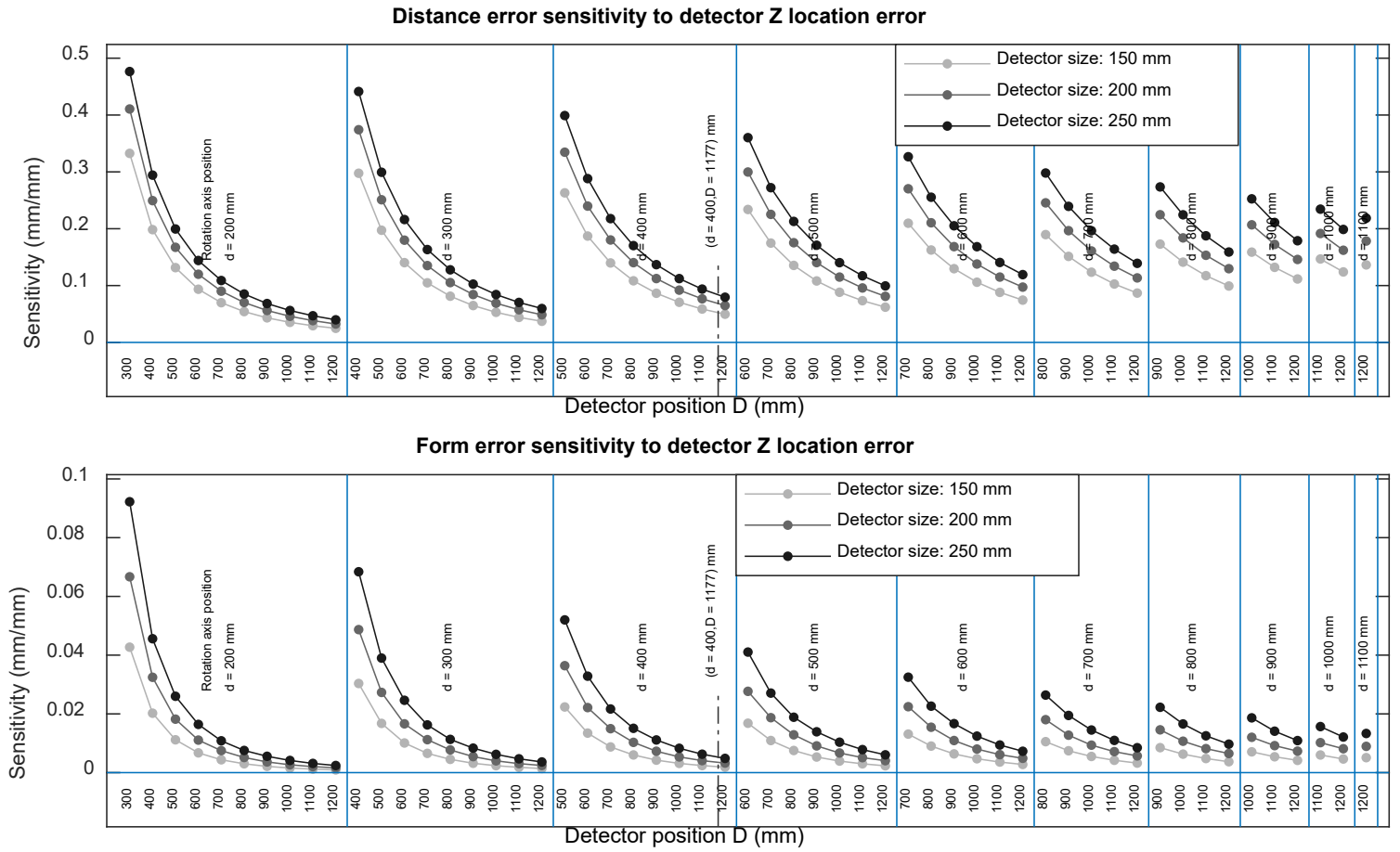

Fig. 4. Distance (top) and form (bottom) error sensitivity to detector $Z$ location error.

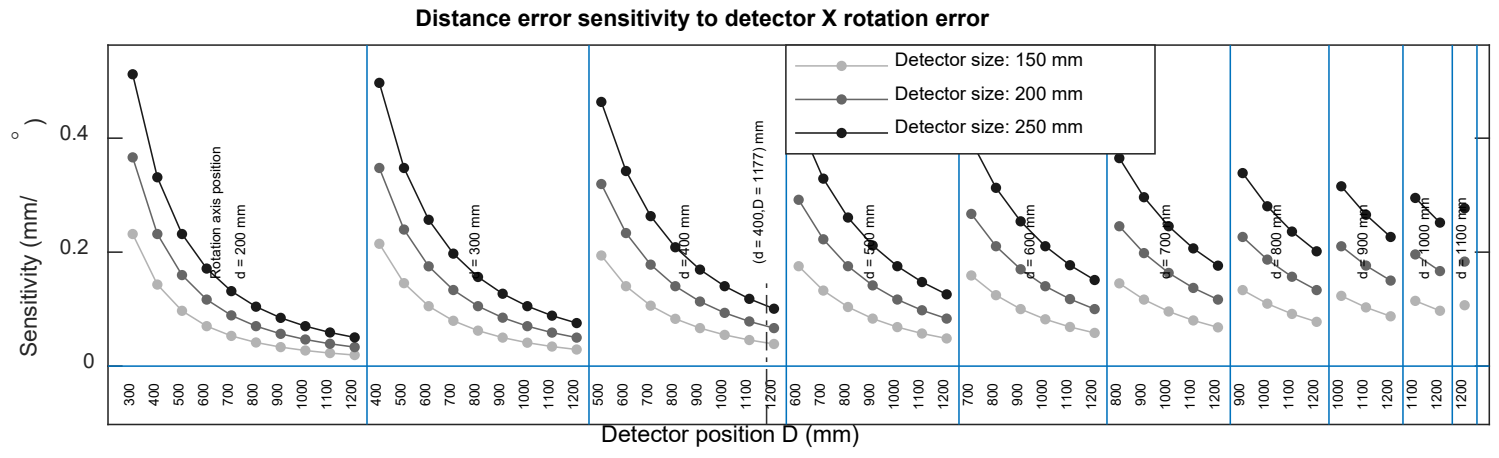

Fig. 5. Distance error sensitivity to detector $X$ rotation error (form error sensitivity is negligible and therefore not shown). 

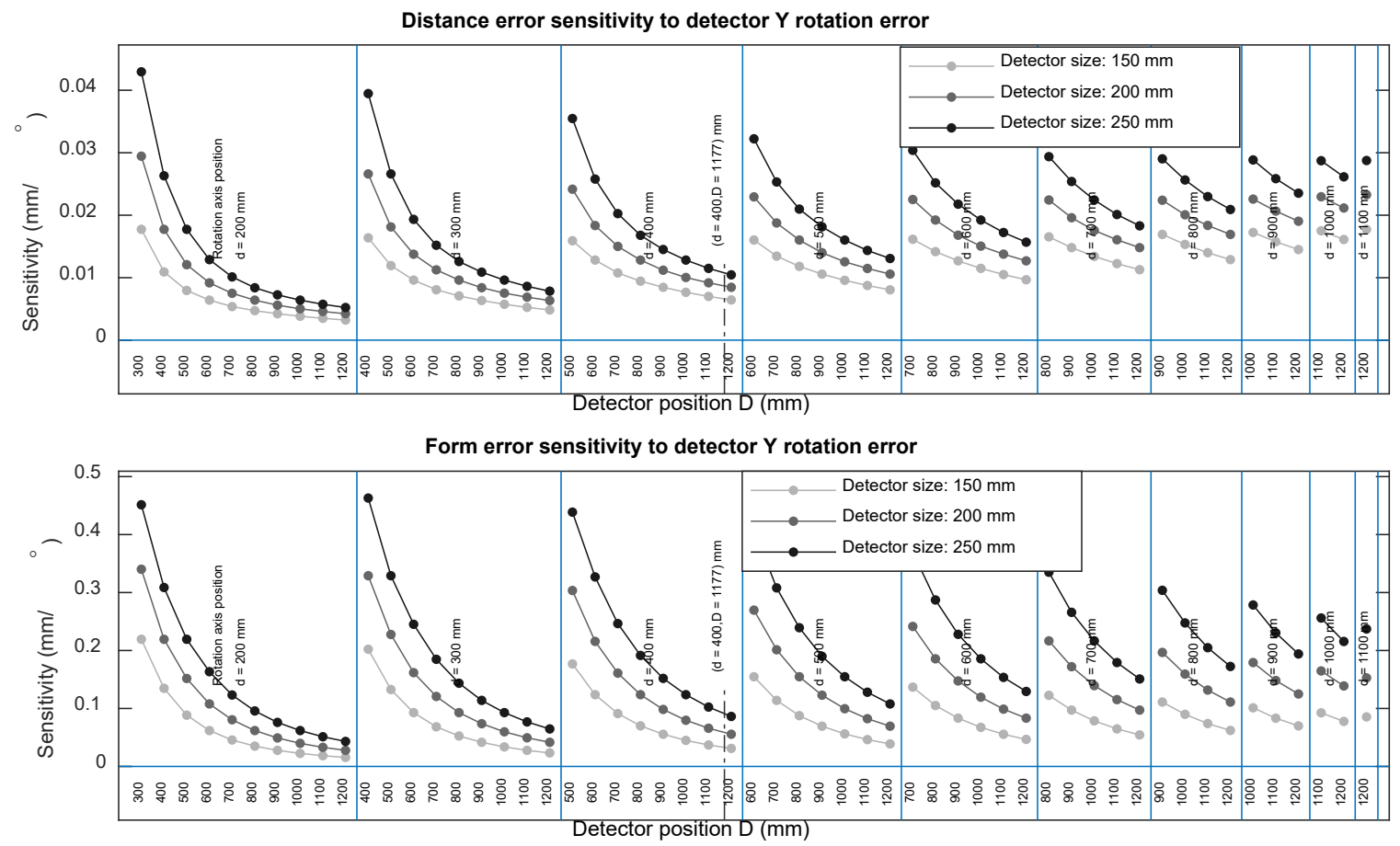

Fig. 6. Distance (top) and form (bottom) error sensitivity to detector $Y$ rotation error.
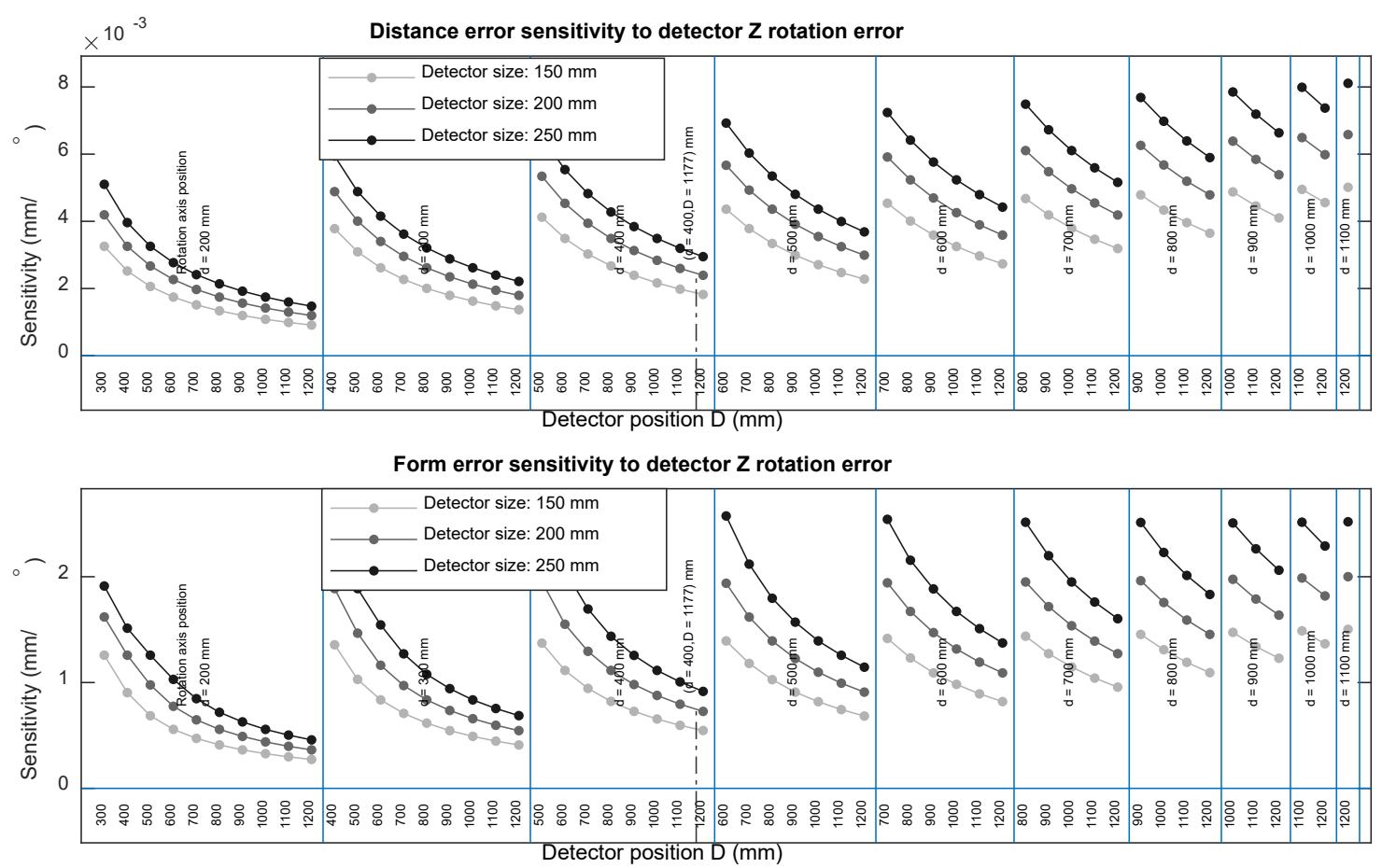

Fig. 7. Distance (top) and form (bottom) error sensitivity to detector $Z$ rotation error. 


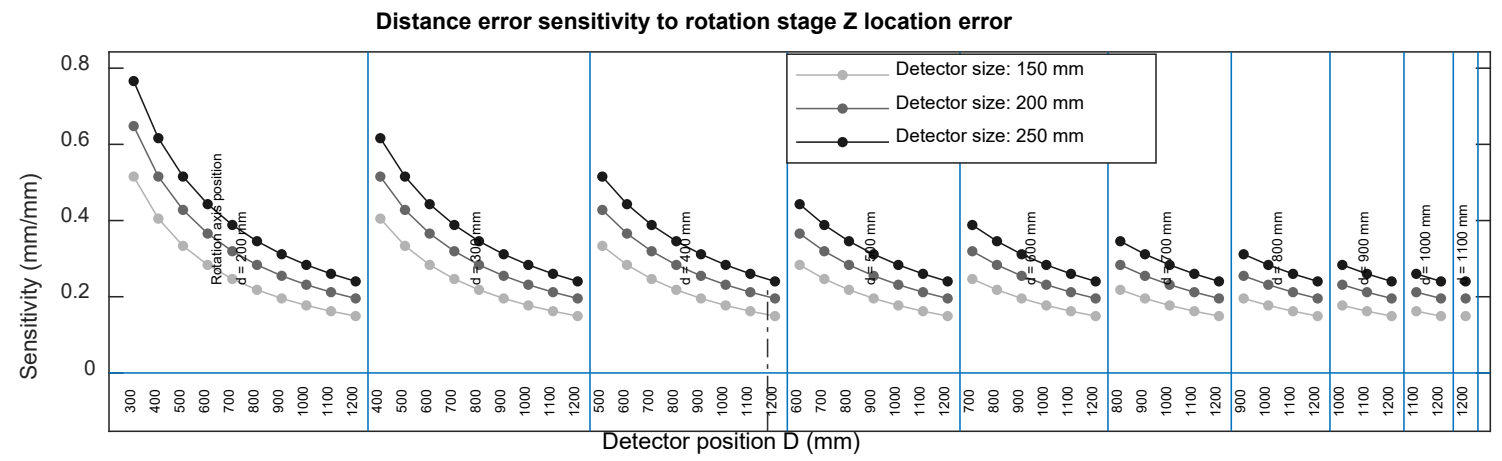

Fig. 8. Distance error sensitivity to rotation stage $Z$ location error (form error sensitivity is negligible and therefore not shown).

\section{Rotation stage error motions}

In this section, we present the distance and form error sensitivities to the different rotation stage error motions described in Part II. As noted in Sec. 3, there may be several pairs of spheres that produce the same distance error sensitivity, some example pairs are identified in the tables in this section. Also, there may be several spheres that produce the same form error sensitivity, one or more such spheres are identified in the tables. Maximum sensitivities shown in the tables are for detector size $s=250 \mathrm{~mm}$ and for the position shown ('near' or 'far').

\subsection{Axial errors}

Figures 9 to 12 show the distance and form error sensitivities to the first four orders of axial errors of the rotation stage. Tables 4 and 5 present the maximum sensitivities, the position ('near' or 'far') where they occur, and the sphere numbers that produce that sensitivity.

Table 4. Distance error sensitivity to axial errors.

\begin{tabular}{|l|l|l|l|l|}
\hline Order & $\begin{array}{l}\text { Maximum } \\
\text { sensitivity }\end{array}$ & Position & $\begin{array}{l}\text { Corresponding sphere } \\
\text { pairs - Cosine }\end{array}$ & $\begin{array}{l}\text { Corresponding sphere } \\
\text { pairs - Sine }\end{array}$ \\
\hline 1 & $0.302 \mathrm{~mm} / \mathrm{mm}$ & Near & $(14,122),(22,114)$ & $(10,118),(18,110)$ \\
\hline 2 & $0.116 \mathrm{~mm} / \mathrm{mm}$ & Near & $\begin{array}{l}(10,18),(14,22), \\
(110,118),(114,122)\end{array}$ & $\begin{array}{l}(12,20),(16,24), \\
(112,120),(116,124)\end{array}$ \\
\hline 3 & $0.029 \mathrm{~mm} / \mathrm{mm}$ & Near & $\begin{array}{l}(12,16),(20,24), \\
(112,116),(120,124)\end{array}$ & $\begin{array}{l}(12,24),(16,20), \\
(112,124),(116,120)\end{array}$ \\
\hline 4 & $0.007 \mathrm{~mm} / \mathrm{mm}$ & Near & $\begin{array}{l}(10,18),(14,22), \\
(112,120),(116,124)\end{array}$ & $\begin{array}{l}(13,21),(17,25), \\
(111,119),(115,123)\end{array}$ \\
\hline
\end{tabular}

Table 5. Form error sensitivity to axial errors.

\begin{tabular}{|l|l|l|l|l|}
\hline Order & $\begin{array}{l}\text { Maximum } \\
\text { sensitivity }\end{array}$ & Position & $\begin{array}{l}\text { Corresponding spheres }- \\
\text { Cosine }\end{array}$ & $\begin{array}{l}\text { Corresponding spheres - } \\
\text { Sine }\end{array}$ \\
\hline 1 & $1.66 \mathrm{~mm} / \mathrm{mm}$ & Near & 14 & 10 \\
\hline 2 & $1.88 \mathrm{~mm} / \mathrm{mm}$ & Far & 10,14 & 12 \\
\hline 3 & $1.81 \mathrm{~mm} / \mathrm{mm}$ & Near & $1,10,12$ & $1,12,14$ \\
\hline 4 & $1.82 \mathrm{~mm} / \mathrm{mm}$ & Far & $10,12,14$ & $10,12,14$ \\
\hline
\end{tabular}



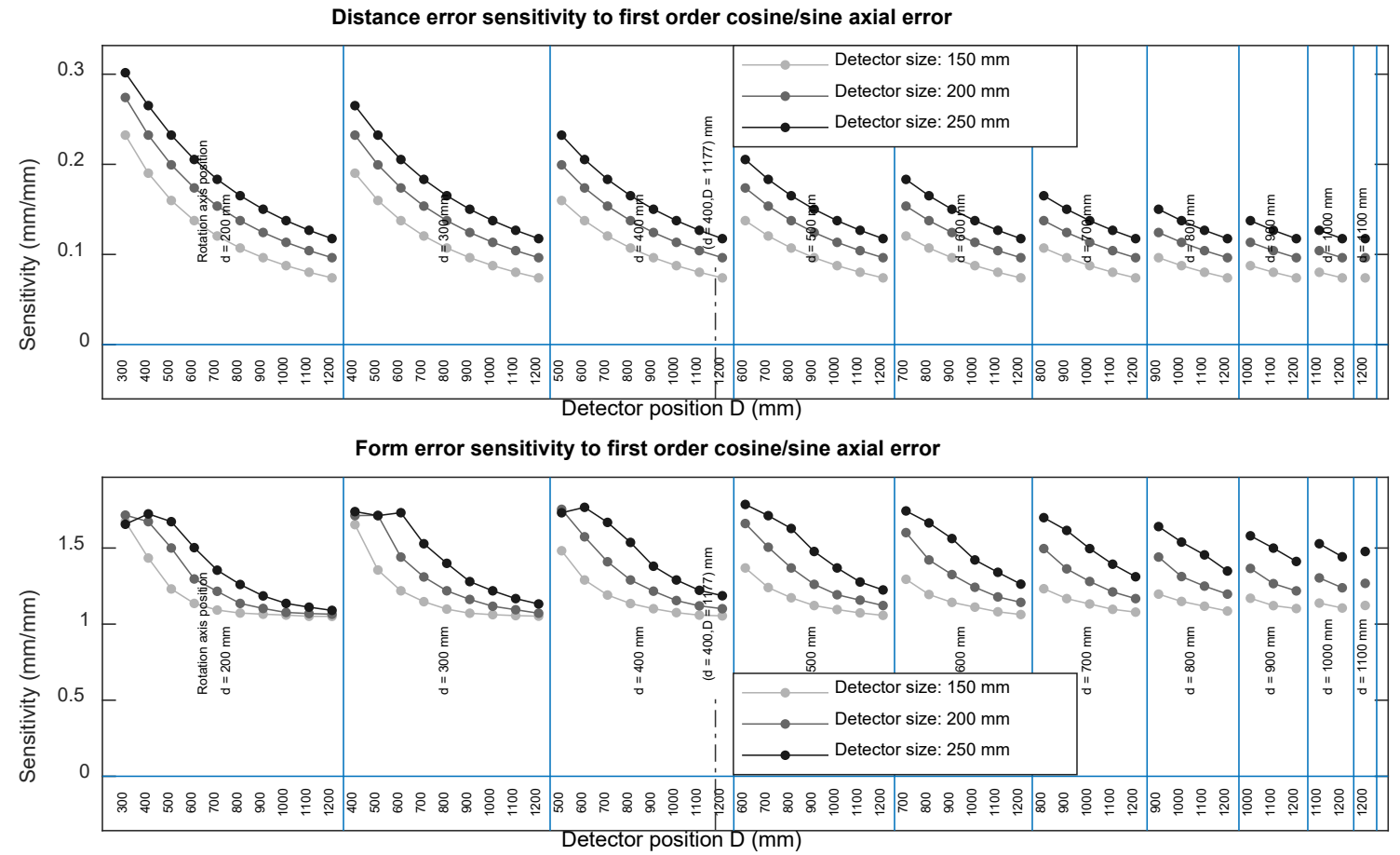

Fig. 9. Distance (top) and form (bottom) error sensitivity to first order cosine and sine axial error.
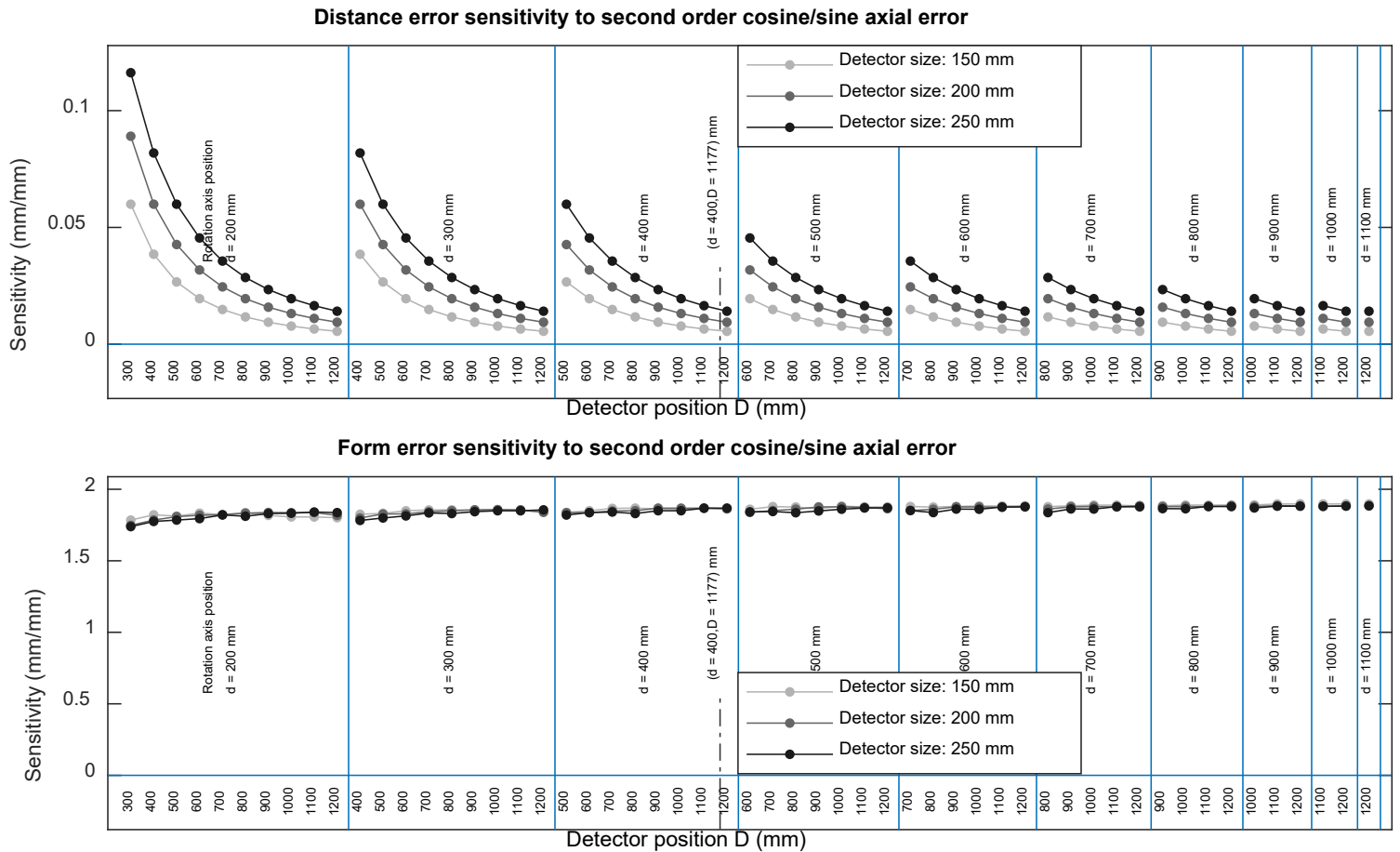

Fig. 10. Distance (top) and form (bottom) error sensitivity to second order cosine and sine axial error. 

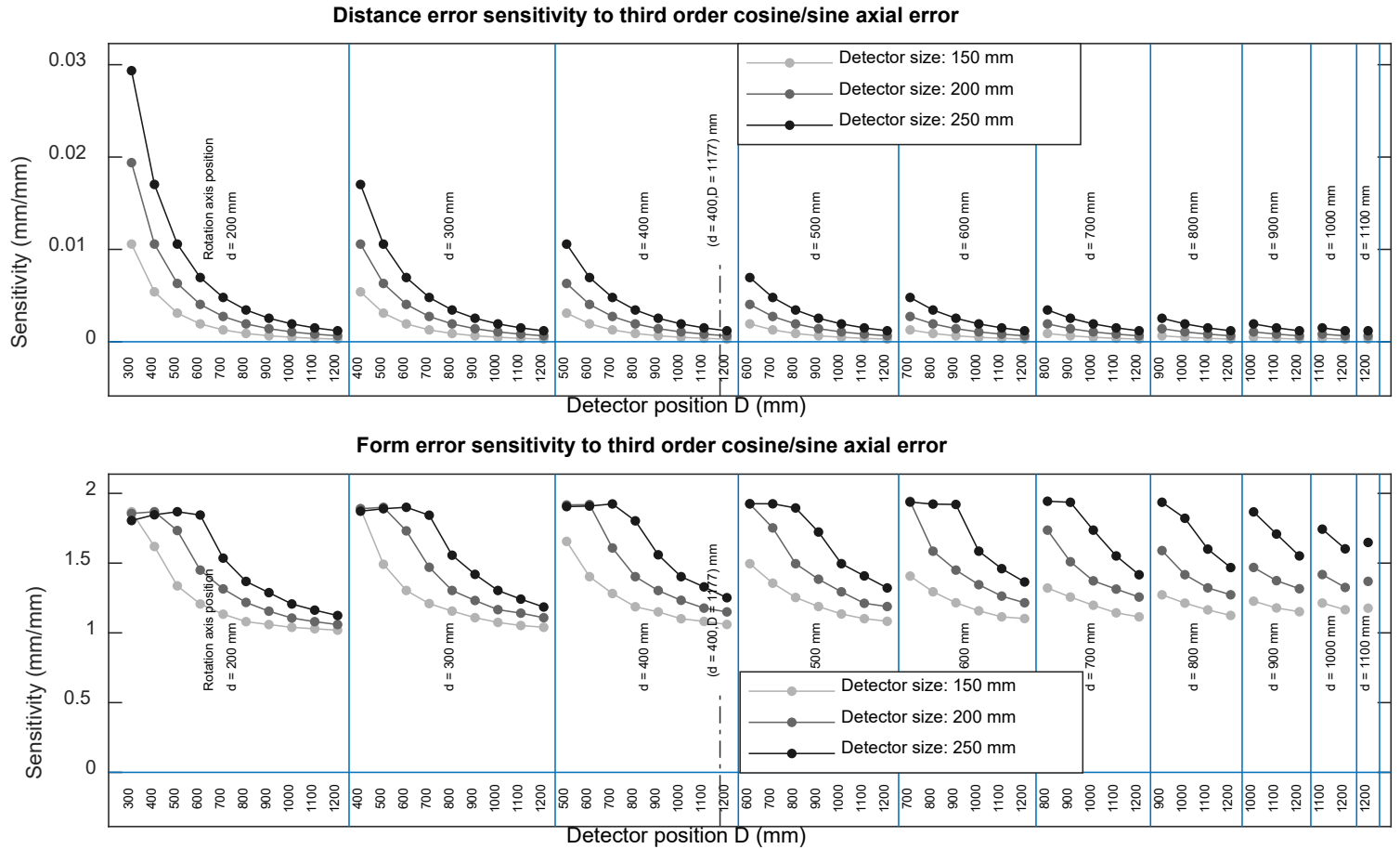

Fig. 11. Distance (top) and form (bottom) error sensitivity to third order cosine and sine axial error.
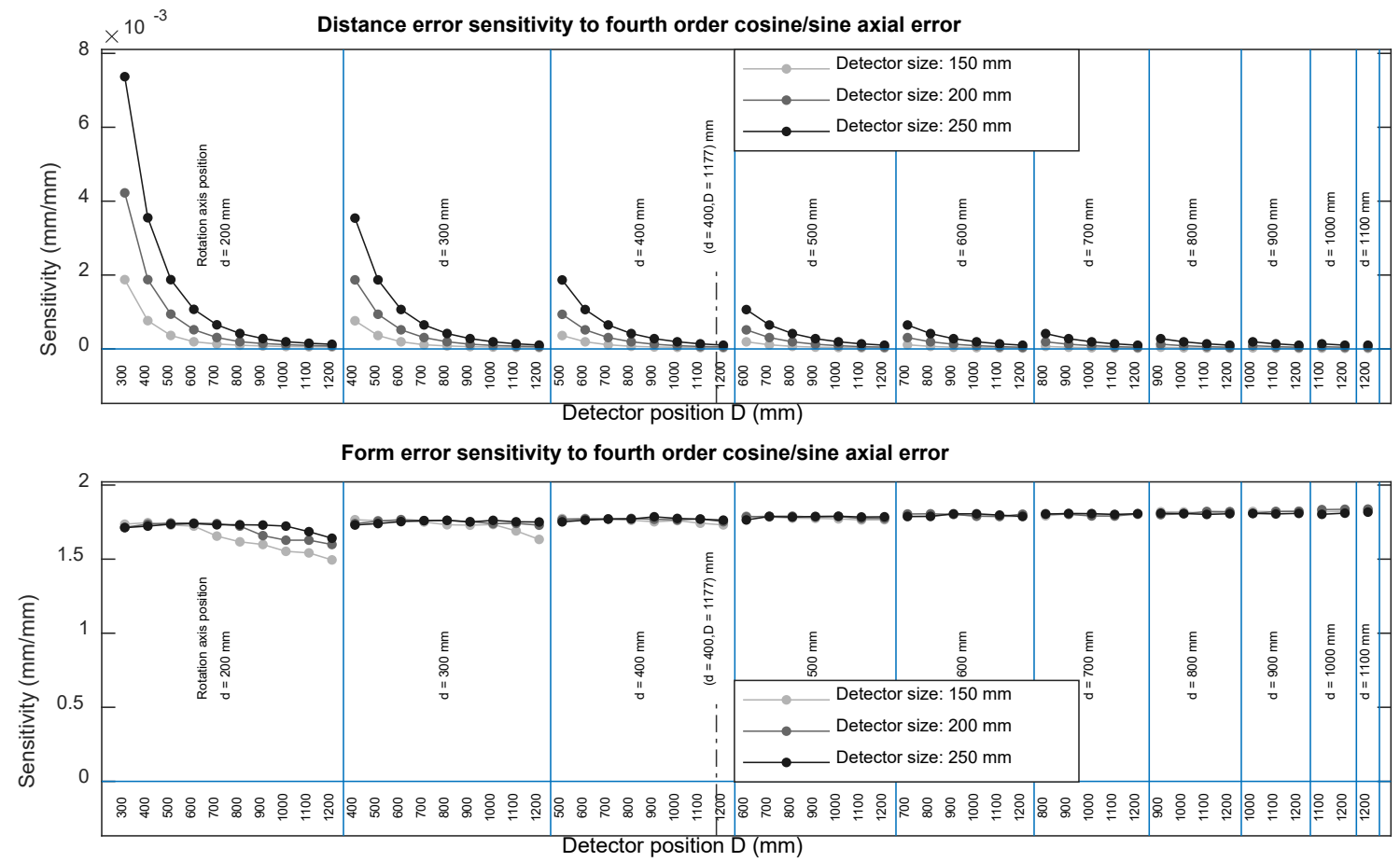

Fig. 12. Distance (top) and form (bottom) error sensitivity to fourth order cosine and sine axial error. 


\subsection{Radial error component along the $X$ axis}

Figures 13 to 16 show the distance and form error sensitivities to the first four orders of radial error motions along $X$. Tables 6 and 7 present the maximum sensitivities, the position ('near' or 'far') where they occur, and the location of the sphere numbers that produce that sensitivity.

Table 6. Distance error sensitivity to radial errors along $X$.

\begin{tabular}{|l|l|l|l|l|}
\hline Order & $\begin{array}{l}\text { Maximum } \\
\text { sensitivity }\end{array}$ & Position & $\begin{array}{l}\text { Corresponding sphere } \\
\text { pairs - Cosine }\end{array}$ & $\begin{array}{l}\text { Corresponding sphere } \\
\text { pairs - Sine }\end{array}$ \\
\hline 1 & $0.094 \mathrm{~mm} / \mathrm{mm}$ & Near & $\begin{array}{l}(10,51),(18,51),(51,110), \\
(51,118)\end{array}$ & $\begin{array}{l}(14,51),(22,51),(51,114), \\
(51,122)\end{array}$ \\
\hline 2 & $0.251 \mathrm{~mm} / \mathrm{mm}$ & Near & $(62,70),(66,74)$ & $(60,68),(64,72)$ \\
\hline 3 & $0.068 \mathrm{~mm} / \mathrm{mm}$ & Near & $(62,74),(66,70)$ & $(62,66),(70,74)$ \\
\hline 4 & $0.019 \mathrm{~mm} / \mathrm{mm}$ & Near & $(61,69),(65,73)$ & $(60,68),(64,72)$ \\
\hline
\end{tabular}

Table 7. Form error sensitivity to radial errors along $X$.

\begin{tabular}{|l|l|l|l|l|}
\hline Order & $\begin{array}{l}\text { Maximum } \\
\text { sensitivity }\end{array}$ & Position & $\begin{array}{l}\text { Corresponding spheres - } \\
\text { Cosine }\end{array}$ & $\begin{array}{l}\text { Corresponding spheres - } \\
\text { Sine }\end{array}$ \\
\hline 1 & $0.54 \mathrm{~mm} / \mathrm{mm}$ & Near & 12 & 12 \\
\hline 2 & $1.63 \mathrm{~mm} / \mathrm{mm}$ & Near & 10,14 & 12 \\
\hline 3 & $2.00 \mathrm{~mm} / \mathrm{mm}$ & Far & 1 & 1 \\
\hline 4 & $1.89 \mathrm{~mm} / \mathrm{mm}$ & Near & $10,12,14$ & $10,12,14$ \\
\hline
\end{tabular}
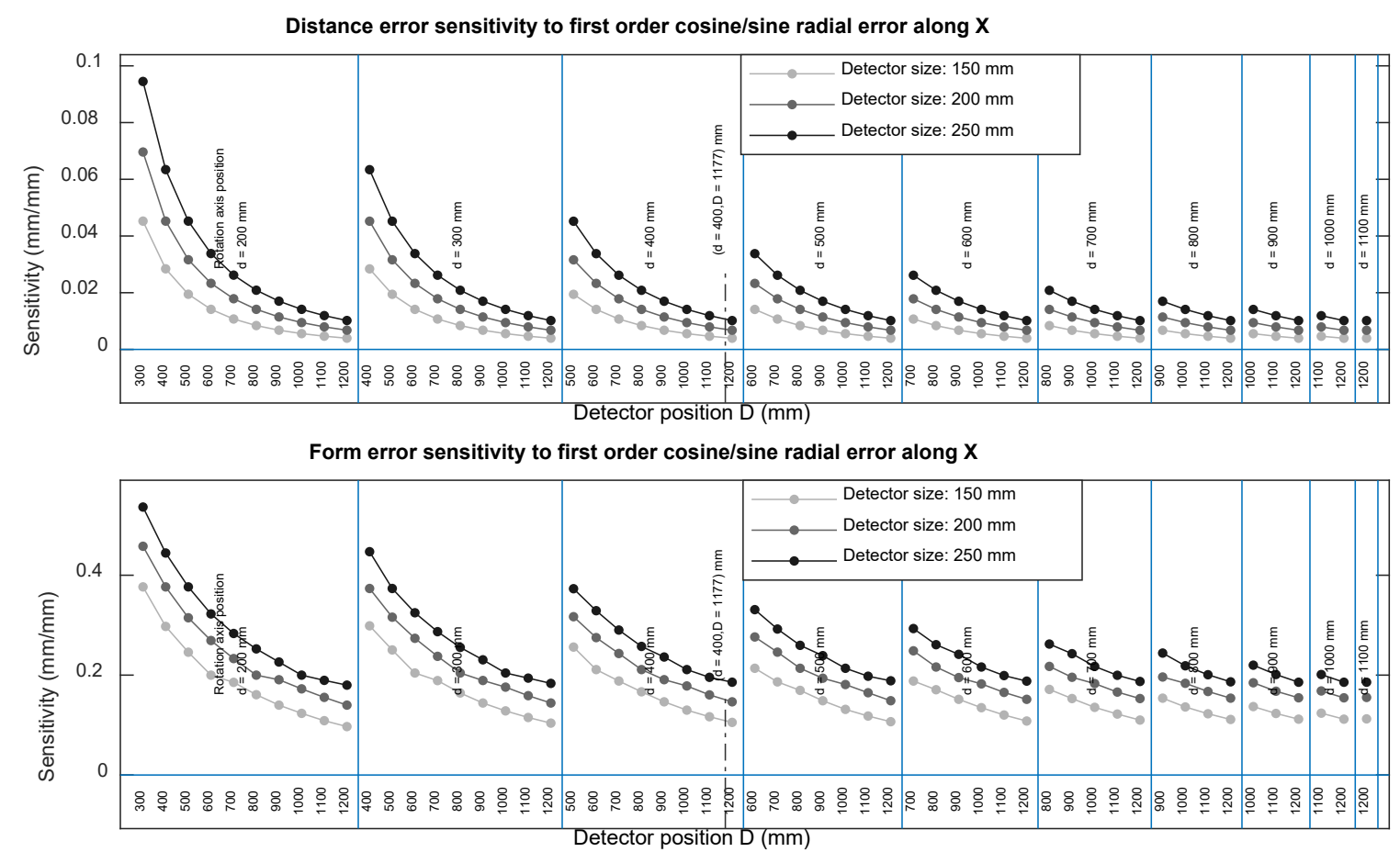

Fig. 13. Distance (top) and form (bottom) error sensitivity to first order cosine and sine radial error along $X$. 

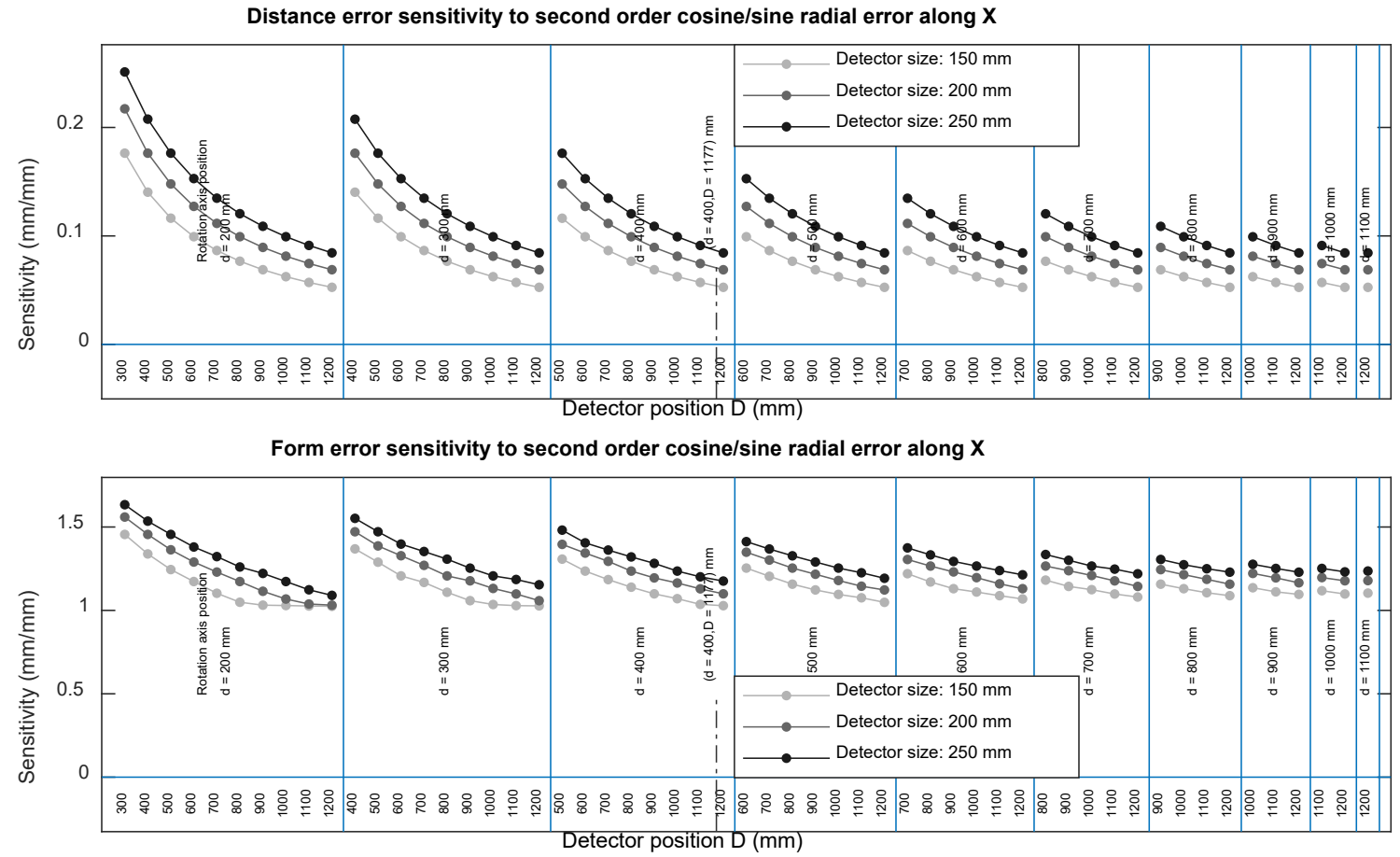

Fig. 14. Distance (top) and form (bottom) error sensitivity to second order cosine and sine radial error along $X$.
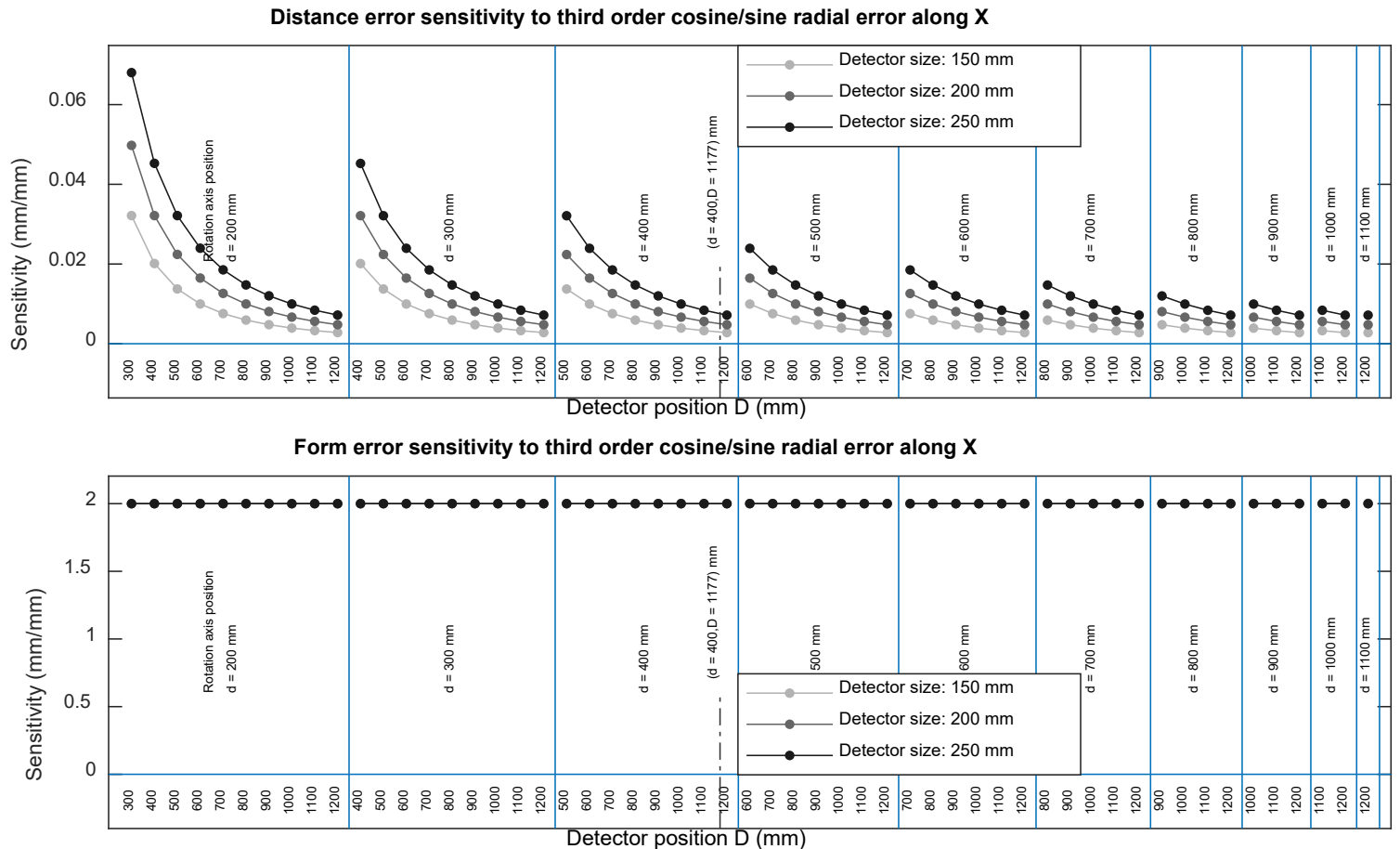

Fig. 15. Distance (top) and form (bottom) error sensitivity to third order cosine and sine radial error along $X$. 

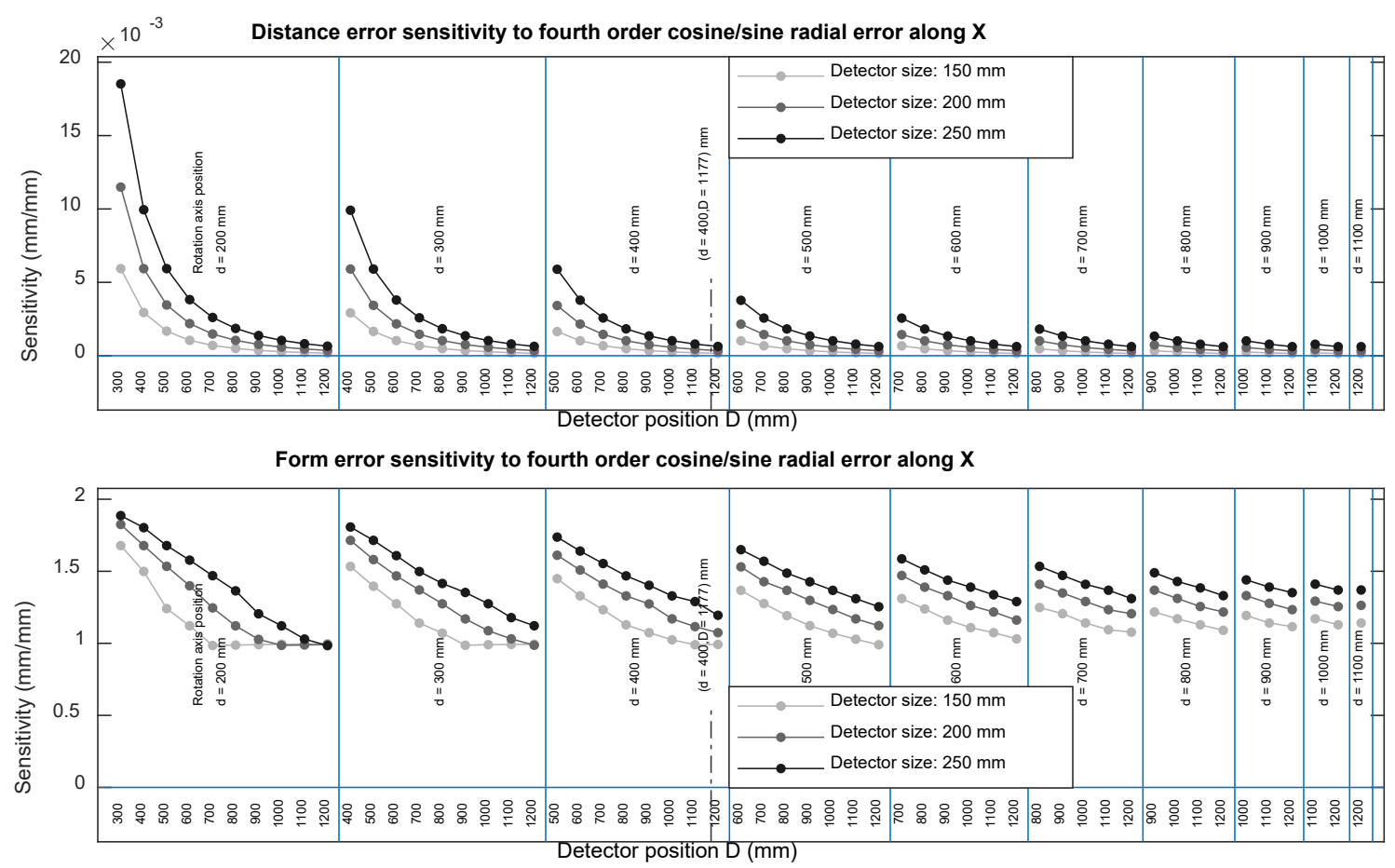

Fig. 16. Distance (top) and form (bottom) error sensitivity to fourth order cosine and sine radial error along $X$.

\subsection{Radial error component along the $Z$ axis}

Figures 17 to 20 show the distance and form error sensitivities to the first four orders of radial errors along $Z$. Tables 8 and 9 present the maximum sensitivities, the position ('near' or 'far') where they occur, and the sphere numbers that produce that sensitivity.

Table 8. Distance error sensitivity to radial errors along $Z$.

\begin{tabular}{|l|l|l|l|l|}
\hline Order & $\begin{array}{l}\text { Maximum } \\
\text { sensitivity }\end{array}$ & Position & $\begin{array}{l}\text { Corresponding sphere } \\
\text { pairs - Cosine }\end{array}$ & $\begin{array}{l}\text { Corresponding sphere } \\
\text { pairs - Sine }\end{array}$ \\
\hline 1 & $0.094 \mathrm{~mm} / \mathrm{mm}$ & Near & $\begin{array}{l}(14,51),(22,51),(51,114), \\
(51,122)\end{array}$ & $\begin{array}{l}(10,51),(18,51),(51,110), \\
(51,118)\end{array}$ \\
\hline 2 & $0.251 \mathrm{~mm} / \mathrm{mm}$ & Near & $(60,68),(64,72)$ & $(62,70),(66,74)$ \\
\hline 3 & $0.068 \mathrm{~mm} / \mathrm{mm}$ & Near & $(62,66),(70,74)$ & $(62,74),(66,70)$ \\
\hline 4 & $0.019 \mathrm{~mm} / \mathrm{mm}$ & Near & $(62,70),(66,74)$ & $(61,69),(65,73)$ \\
\hline
\end{tabular}

Table 9. Form error sensitivity to radial errors along $Z$.

\begin{tabular}{|l|l|l|l|l|}
\hline Order & $\begin{array}{l}\text { Maximum } \\
\text { sensitivity }\end{array}$ & Position & $\begin{array}{l}\text { Corresponding spheres - } \\
\text { Cosine }\end{array}$ & $\begin{array}{l}\text { Corresponding spheres - } \\
\text { Sine }\end{array}$ \\
\hline 1 & $0.54 \mathrm{~mm} / \mathrm{mm}$ & Near & 12 & 12 \\
\hline 2 & $0.60 \mathrm{~mm} / \mathrm{mm}$ & Near & 10,14 & 12 \\
\hline 3 & $0.74 \mathrm{~mm} / \mathrm{mm}$ & Near & 14 & 10 \\
\hline 4 & $0.75 \mathrm{~mm} / \mathrm{mm}$ & Near & $10,12,14$ & $10,12,14$ \\
\hline
\end{tabular}



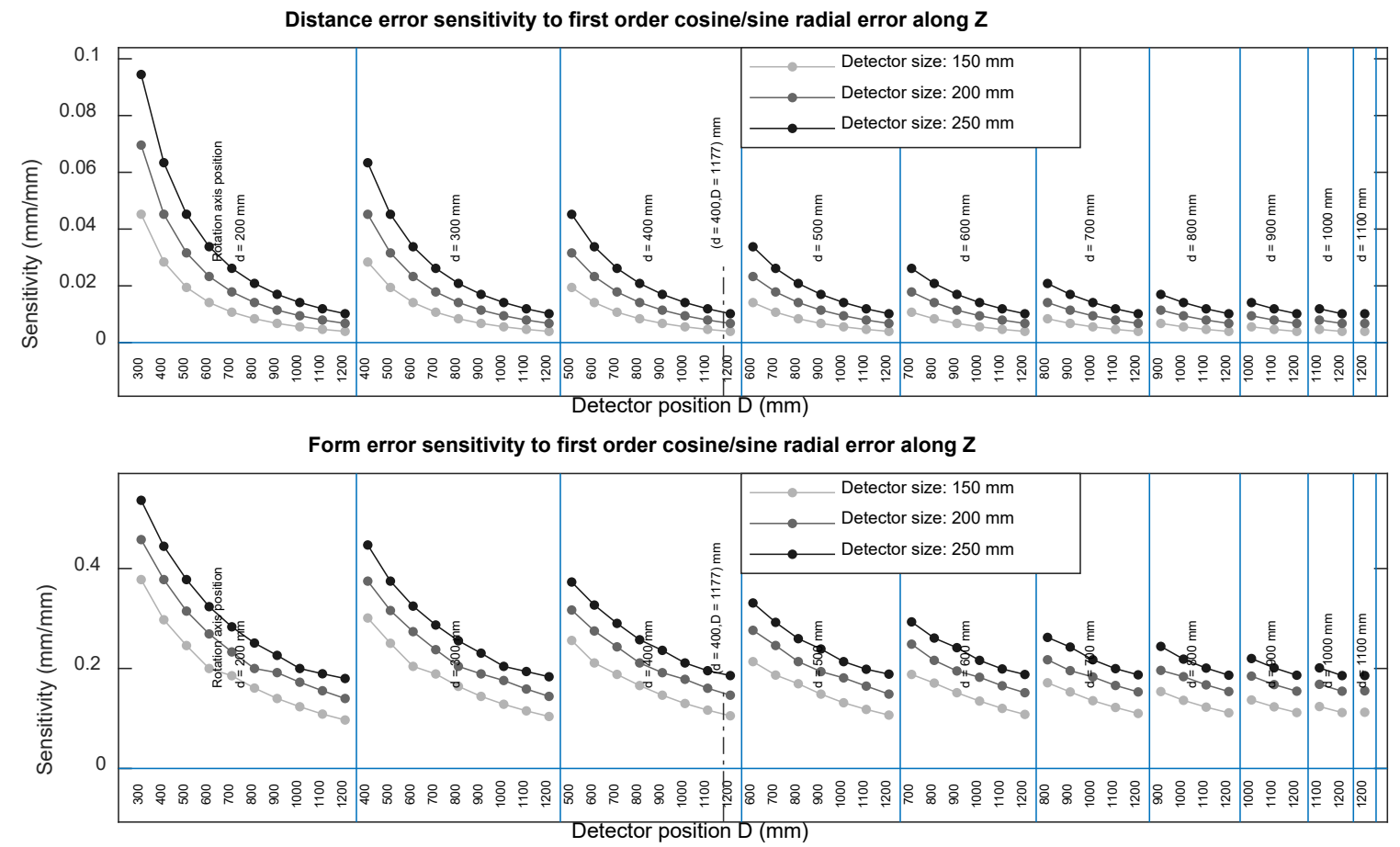

Fig. 17. Distance (top) and form (bottom) error sensitivity to first order cosine and sine radial error along $Z$.
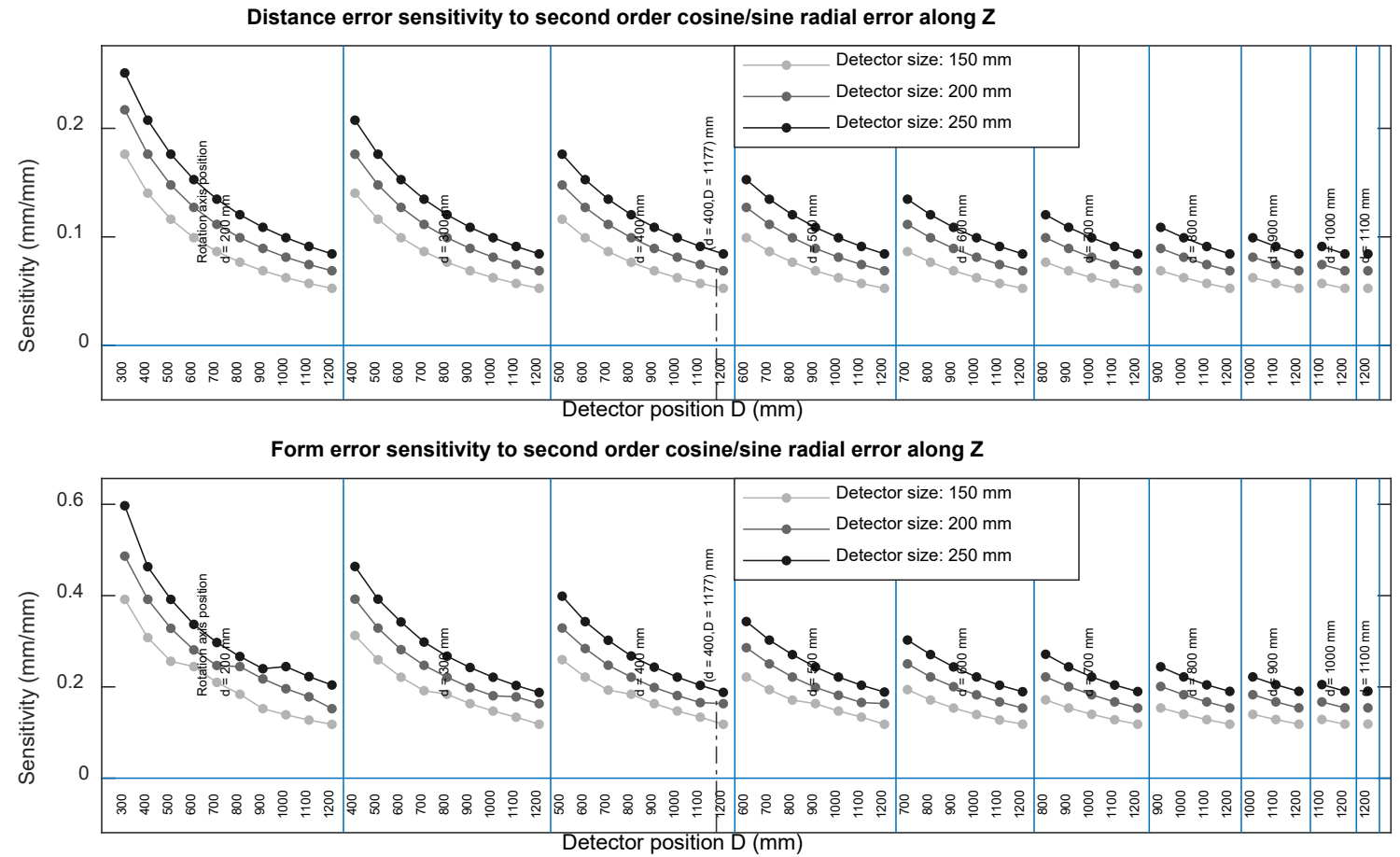

Fig. 18. Distance (top) and form (bottom) error sensitivity to second order cosine and sine radial error along $Z$. 

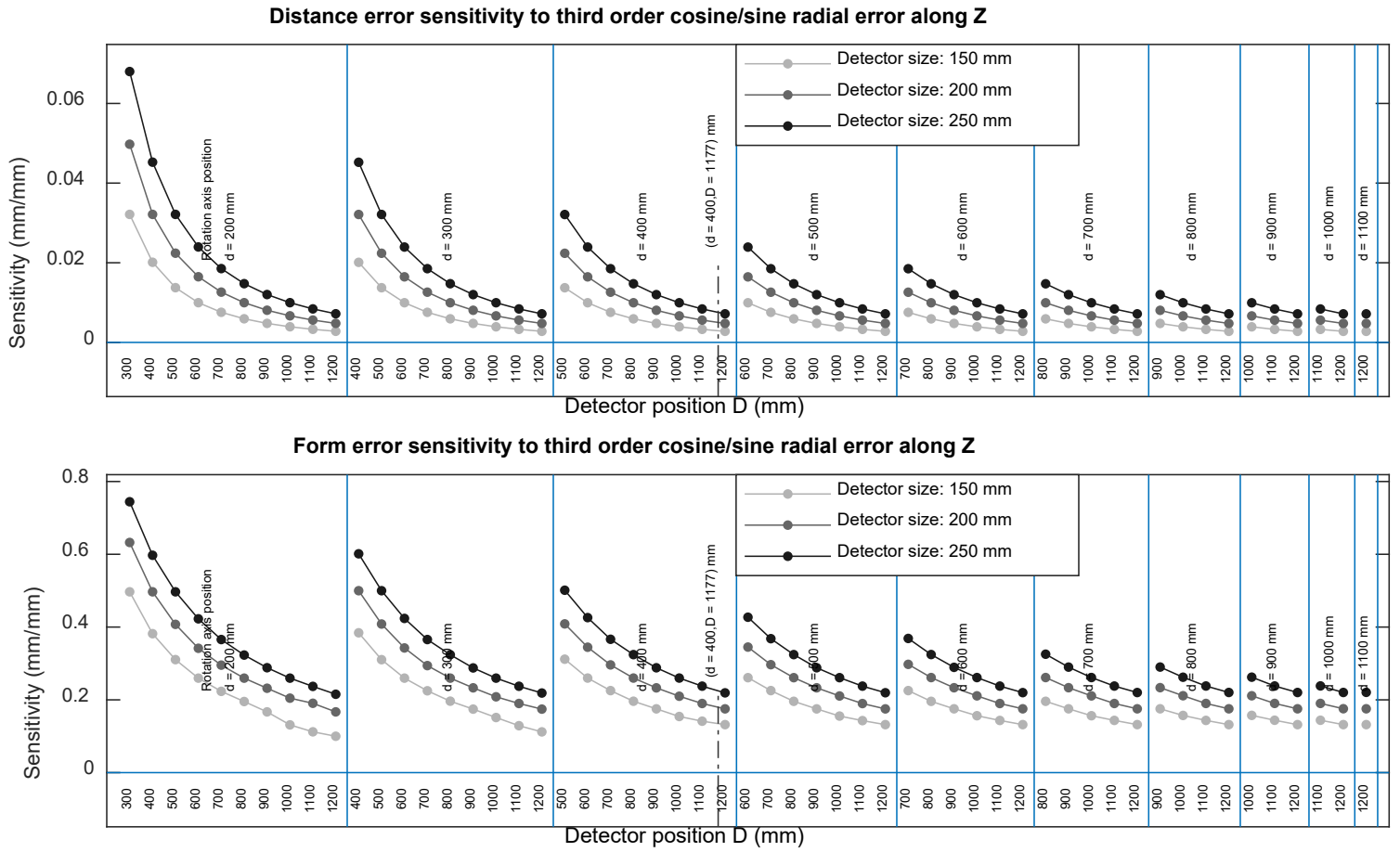

Fig. 19. Distance (top) and form (bottom) error sensitivity to third order cosine and sine radial error along $Z$.
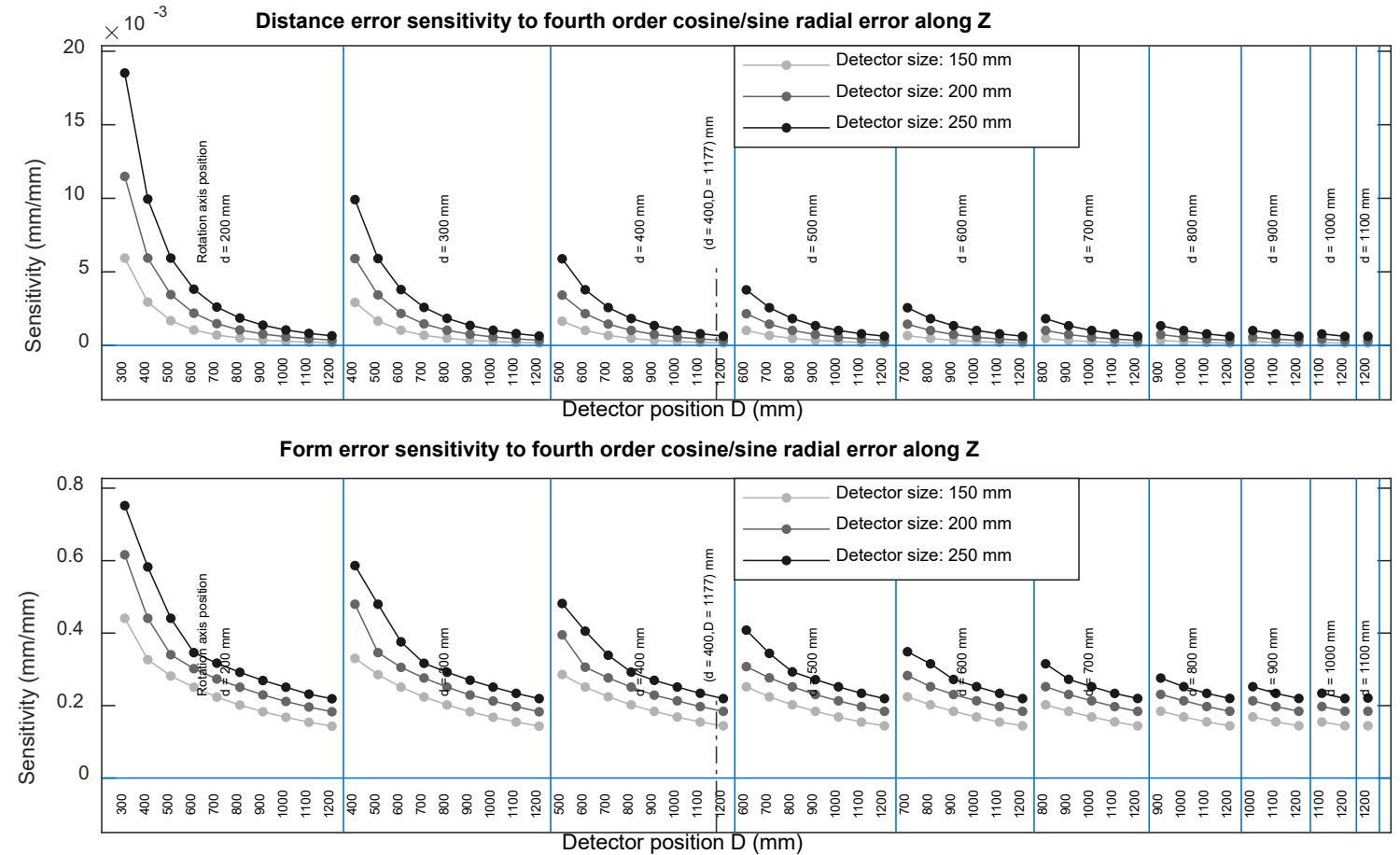

Fig. 20. Distance (top) and form (bottom) error sensitivity to fourth order cosine and sine radial error along $Z$. 


\subsection{Wobble about the $X$ axis}

Figures 21 to 24 show the distance and form error sensitivities to the first four orders of wobble about the $\mathrm{X}$ axis. Tables 10 and 11 present the maximum sensitivities, the position ('near' or 'far') where they occur, and the sphere numbers that produce that sensitivity.

Table 10. Distance error sensitivity to wobble about the $X$ axis.

\begin{tabular}{|l|l|l|l|l|}
\hline Order & $\begin{array}{l}\text { Maximum } \\
\text { sensitivity }\end{array}$ & Position & $\begin{array}{l}\text { Corresponding sphere } \\
\text { pairs - Cosine }\end{array}$ & $\begin{array}{l}\text { Corresponding sphere } \\
\text { pairs - Sine }\end{array}$ \\
\hline 1 & $1.130 \mathrm{~mm} /{ }^{\circ}$ & Far & $(14,122),(22,114)$ & $(10,118),(18,110)$ \\
\hline 2 & $0.406 \mathrm{~mm} /{ }^{\circ}$ & Near & $\begin{array}{l}(10,18),(14,22), \\
(110,118),(114,122)\end{array}$ & $\begin{array}{l}(12,20),(16,24), \\
(112,120),(116,124)\end{array}$ \\
\hline 3 & $0.103 \mathrm{~mm} /{ }^{\circ}$ & Near & $(20,24),(112,116)$ & $(12,24),(116,120)$ \\
\hline 4 & $0.026 \mathrm{~mm} /{ }^{\circ}$ & Near & $\begin{array}{l}(10,18),(14,22), \\
(112,120),(116,124)\end{array}$ & $\begin{array}{l}(13,21),(17,25), \\
(111,119),(115,123)\end{array}$ \\
\hline
\end{tabular}

Table 11. Form error sensitivity to wobble about the $X$ axis.

\begin{tabular}{|l|l|l|l|l|}
\hline Order & $\begin{array}{l}\text { Maximum } \\
\text { sensitivity }\end{array}$ & Position & $\begin{array}{l}\text { Corresponding spheres - } \\
\text { Cosine }\end{array}$ & $\begin{array}{l}\text { Corresponding spheres - } \\
\text { Sine }\end{array}$ \\
\hline 1 & $1.88 \mathrm{~mm} /{ }^{\circ}$ & Far & 12 & 12 \\
\hline 2 & $2.01 \mathrm{~mm} /{ }^{\circ}$ & Far & 10,14 & 12 \\
\hline 3 & $2.89 \mathrm{~mm} /{ }^{\circ}$ & Far & 14 & 10 \\
\hline 4 & $2.31 \mathrm{~mm} /{ }^{\circ}$ & Far & $10,12,14$ & $10,12,14$ \\
\hline
\end{tabular}
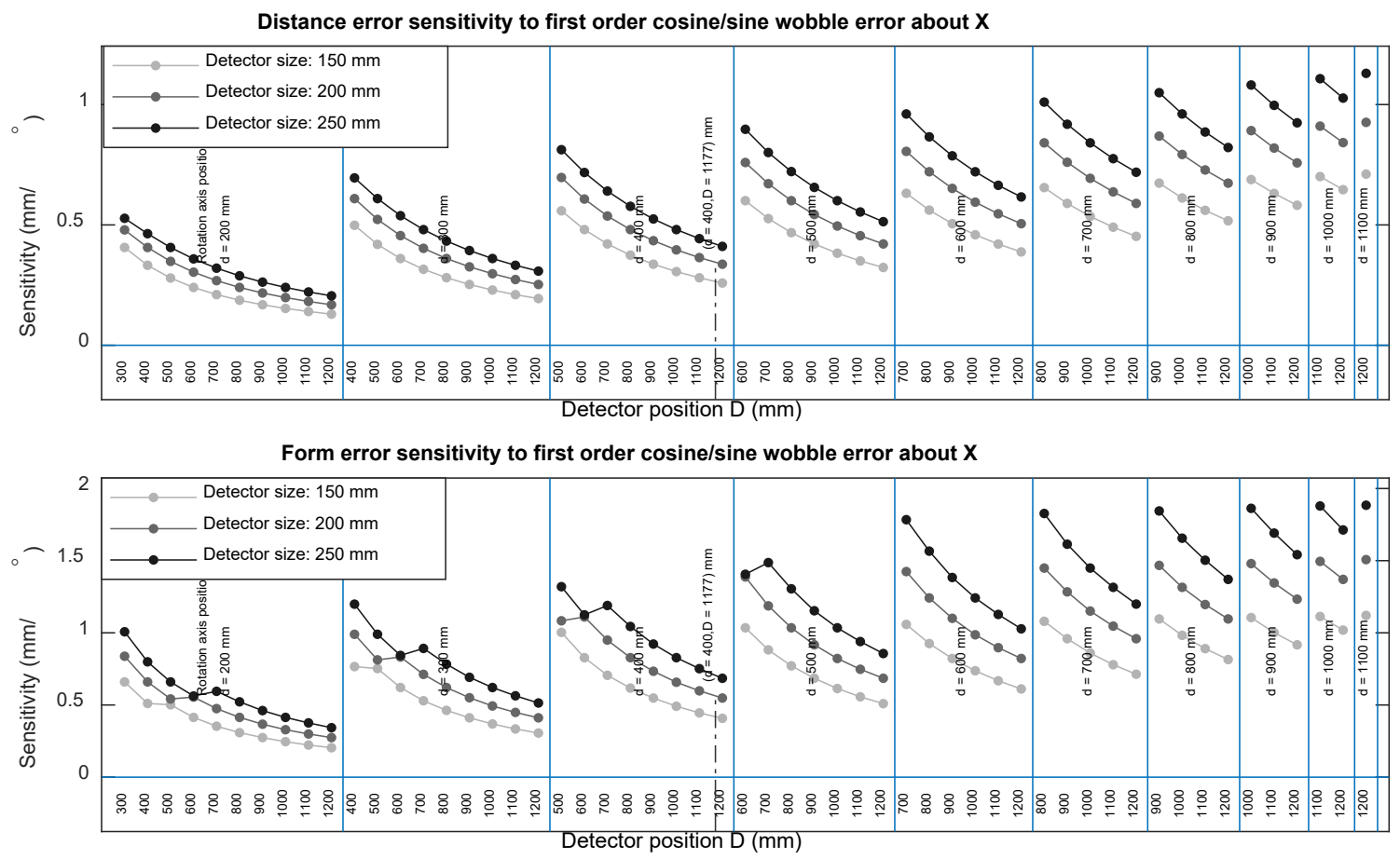

Fig. 21. Distance (top) and form (bottom) error sensitivity to first order cosine and sine wobble error about $X$. 

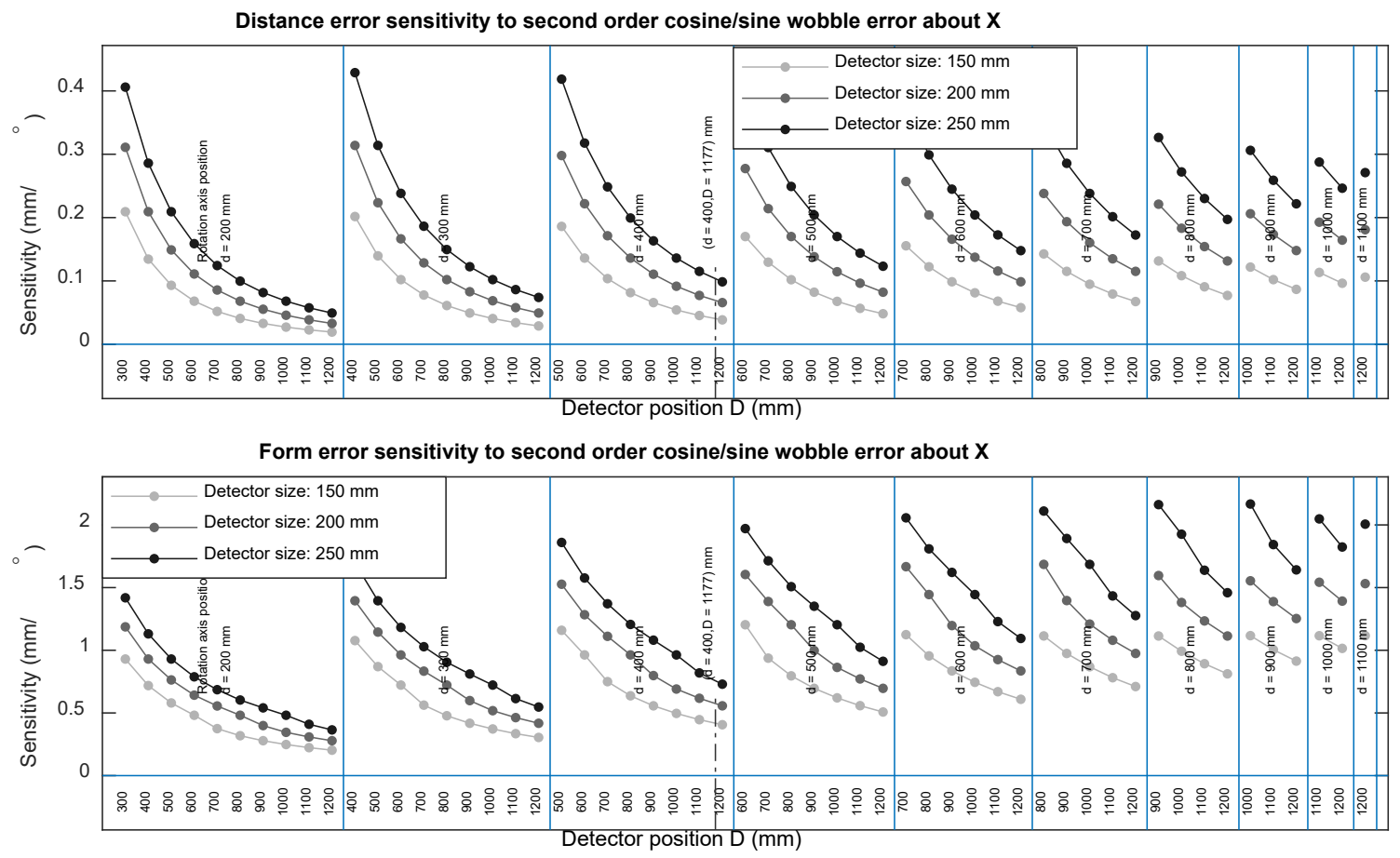

Fig. 22. Distance (top) and form (bottom) error sensitivity to second order cosine and sine wobble error about $X$.
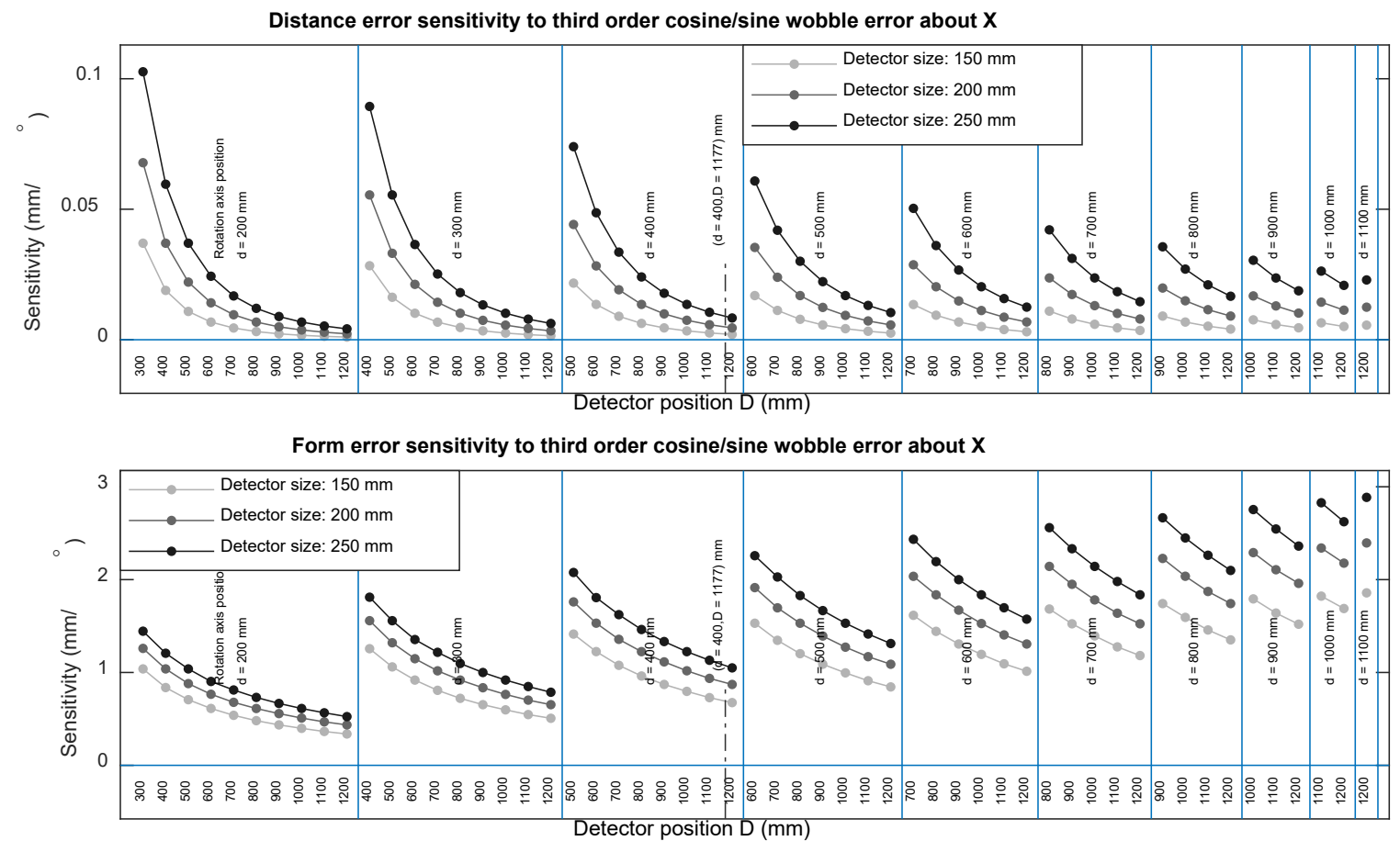

Fig. 23. Distance (top) and form (bottom) error sensitivity to third order cosine and sine wobble error about $X$. 

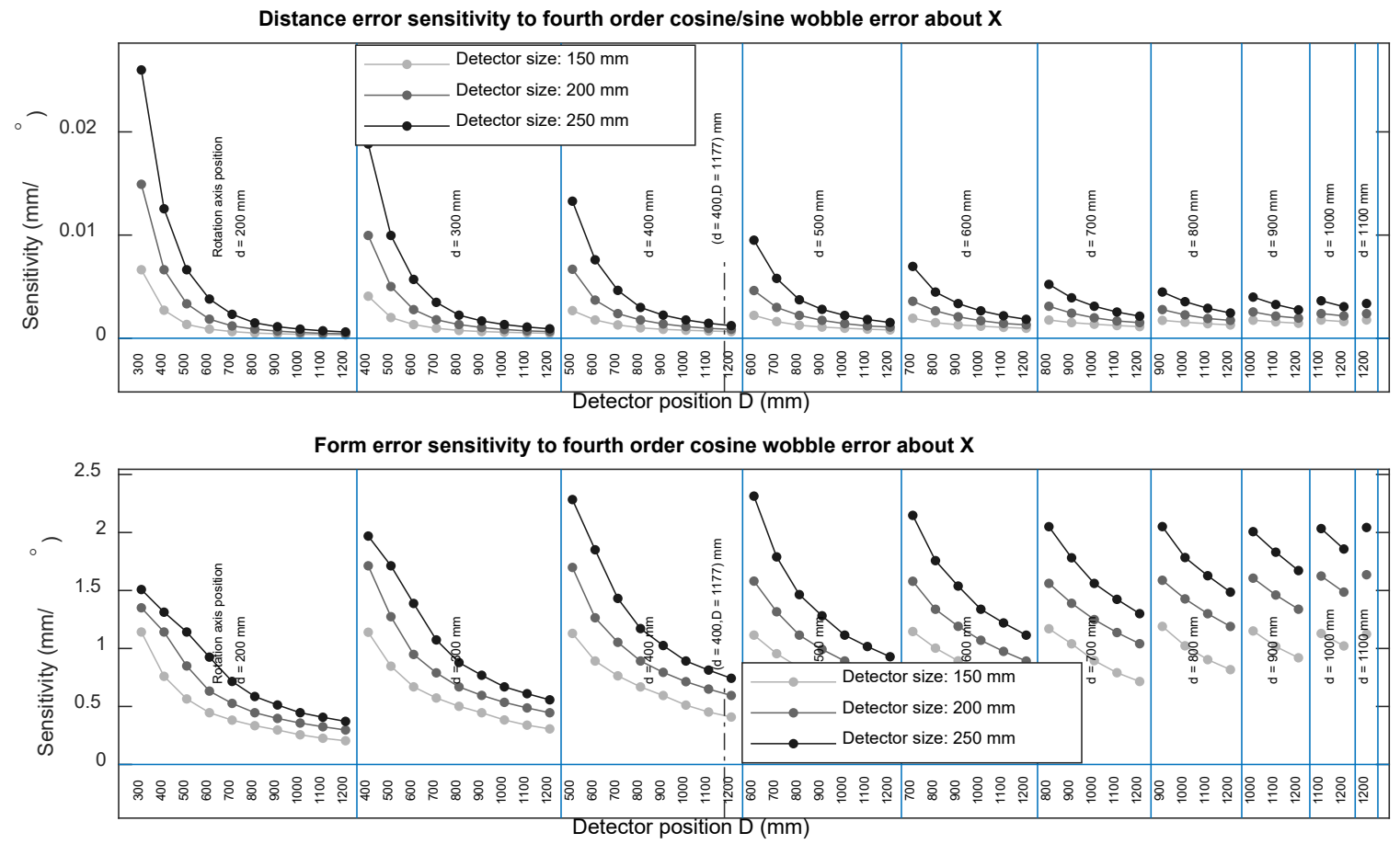

Fig. 24. Distance (top) and form (bottom) error sensitivity to fourth order cosine and sine wobble error about $X$ (Note: form error for sine is similar but not identical to cosine).

\subsection{Wobble about the $Z$ axis}

Figures 25 to 28 show the distance and form error sensitivities to the first four orders of wobble about the $Z$ axis; figures for negligible errors won't be shown. Tables 12 and 13 present the maximum sensitivities, the position ('near' or 'far') where they occur, and the sphere numbers that produce that sensitivity.

Table 12. Distance error sensitivity to wobble about the $Z$ axis.

\begin{tabular}{|l|l|l|l|l|}
\hline Order & $\begin{array}{l}\text { Maximum } \\
\text { sensitivity }\end{array}$ & Position & $\begin{array}{l}\text { Corresponding spheres - } \\
\text { Cosine }\end{array}$ & $\begin{array}{l}\text { Corresponding spheres - } \\
\text { Sine }\end{array}$ \\
\hline 1 & $1.128 \mathrm{~mm} /{ }^{\circ}$ & Far & $(10,118),(18,110)$ & $(14,122),(22,114)$ \\
\hline $2,3,4$ & Negligible & & & \\
\hline
\end{tabular}

Table 13. Form error sensitivity to wobble about the $Z$ axis.

\begin{tabular}{|l|l|l|l|l|}
\hline Order & $\begin{array}{l}\text { Maximum } \\
\text { sensitivity }\end{array}$ & Position & $\begin{array}{l}\text { Corresponding spheres - } \\
\text { Cosine }\end{array}$ & $\begin{array}{l}\text { Corresponding spheres - } \\
\text { Sine }\end{array}$ \\
\hline 1 & $1.88 \mathrm{~mm} /{ }^{\circ}$ & Far & 10,12 & 12 \\
\hline 2 & $2.54 \mathrm{~mm} /{ }^{\circ}$ & Far & 10,14 & 12 \\
\hline 3 & $4.63 \mathrm{~mm} /{ }^{\circ}$ & Far & 12 & 12,14 \\
\hline 4 & $2.81 \mathrm{~mm} /{ }^{\circ}$ & Far & $10,12,14$ & $10,12,14$ \\
\hline
\end{tabular}



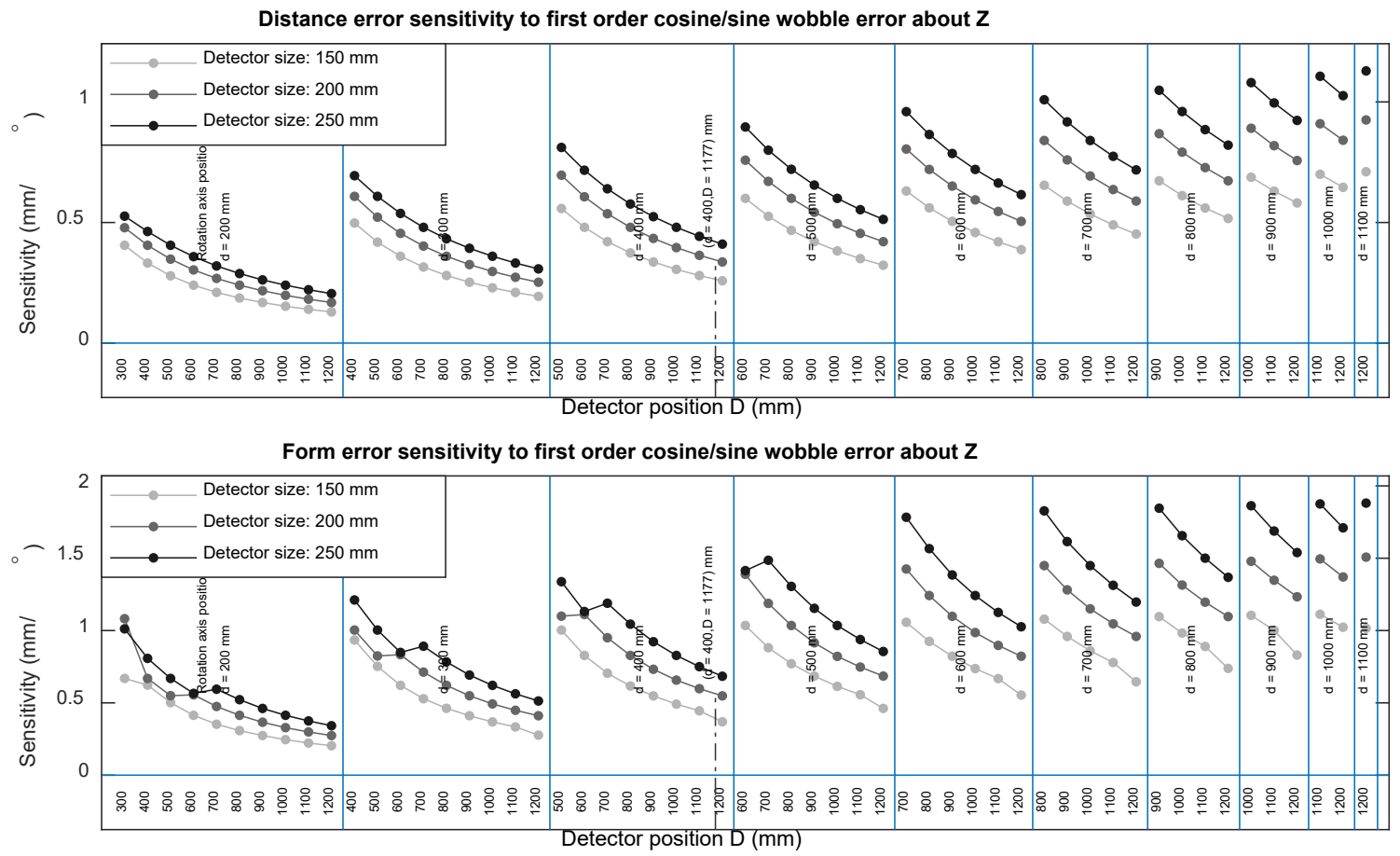

Fig. 25. Distance (top) and form (bottom) error sensitivity to first order cosine and sine wobble error about $Z$.

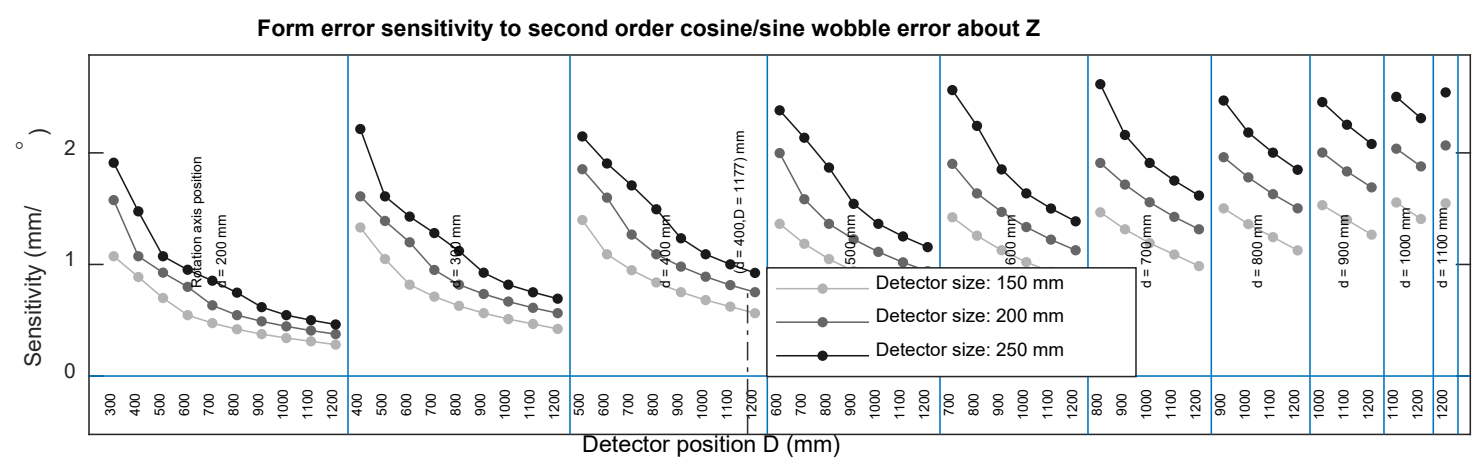

Fig. 26. Form error sensitivity to second order cosine and sine wobble error about $Z$.

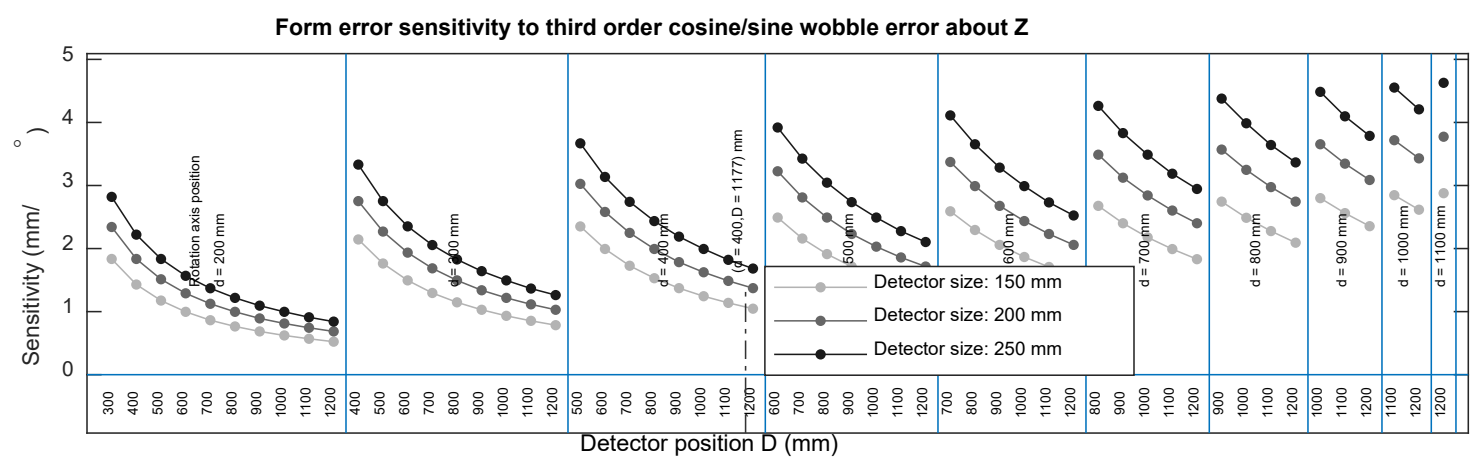

Fig. 27. Form error sensitivity to third order cosine and sine wobble error about $Z$. 


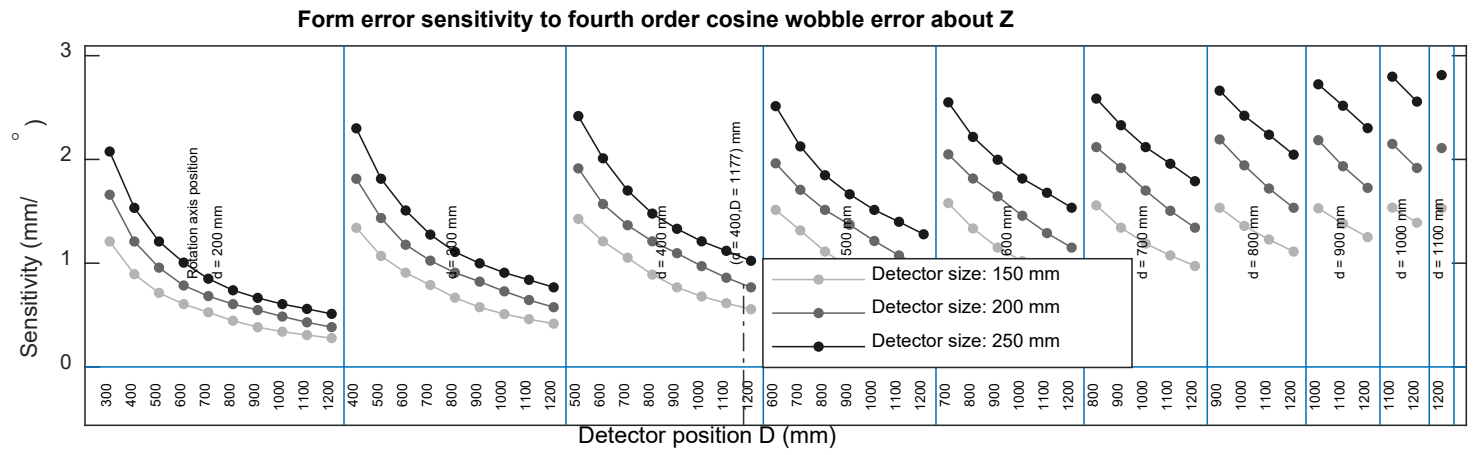

Fig. 28. Form error sensitivity to fourth order cosine wobble error about $Z$ (Note: form error for sine is similar but not identical to cosine).

\subsection{Scale (angular indexing) errors in the rotation stage encoder}

Figures 29 to 32 show the distance and form error sensitivities to the first four orders of wobble about the $\mathrm{Z}$ axis. Tables 14 and 15 present the maximum sensitivities, the position ('near' or 'far') where they occur, and the sphere numbers that produce that sensitivity.

Table 14. Distance error sensitivity to scale (angular indexing) errors.

\begin{tabular}{|l|l|l|l|l|}
\hline Order & $\begin{array}{l}\text { Maximum } \\
\text { sensitivity }\end{array}$ & Position & $\begin{array}{l}\text { Corresponding sphere } \\
\text { pairs - Cosine }\end{array}$ & $\begin{array}{l}\text { Corresponding sphere } \\
\text { pairs - Sine }\end{array}$ \\
\hline 1 & $0.257 \mathrm{~mm} /{ }^{\circ}$ & Near & $(10 / 110),(18 / 118)$ & $(14 / 114),(22 / 122)$ \\
\hline 2 & $1.619 \mathrm{~mm} /^{\circ}$ & Far & $\begin{array}{l}(12 / 20),(16 / 24), \\
(112 / 120),(116 / 124)\end{array}$ & $\begin{array}{l}(10 / 18),(14 / 22), \\
(110 / 118),(114 / 122)\end{array}$ \\
\hline 3 & $0.237 \mathrm{~mm} /{ }^{\circ}$ & Near & $(62 / 74),(66 / 70)$ & $(62 / 66),(70 / 74)$ \\
\hline 4 & $0.065 \mathrm{~mm} /^{\circ}$ & Near & $(63 / 71),(67 / 75)$ & $(62 / 70),(66 / 74)$ \\
\hline
\end{tabular}

Table 15. Form error sensitivity to scale (angular indexing) errors.

\begin{tabular}{|l|l|l|l|l|}
\hline Order & $\begin{array}{l}\text { Maximum } \\
\text { sensitivity }\end{array}$ & Position & $\begin{array}{l}\text { Corresponding sphere } \\
\text { pairs - Cosine }\end{array}$ & $\begin{array}{l}\text { Corresponding sphere } \\
\text { pairs - Sine }\end{array}$ \\
\hline 1 & $1.70 \mathrm{~mm} /{ }^{\circ}$ & Far & 14 & 10 \\
\hline 2 & $1.74 \mathrm{~mm} /{ }^{\circ}$ & Far & 10,14 & 12 \\
\hline 3 & $2.03 \mathrm{~mm} /{ }^{\circ}$ & Far & 14 & 10 \\
\hline 4 & $3.27 \mathrm{~mm} /{ }^{\circ}$ & Far & $10,12,14$ & $10,12,14$ \\
\hline
\end{tabular}



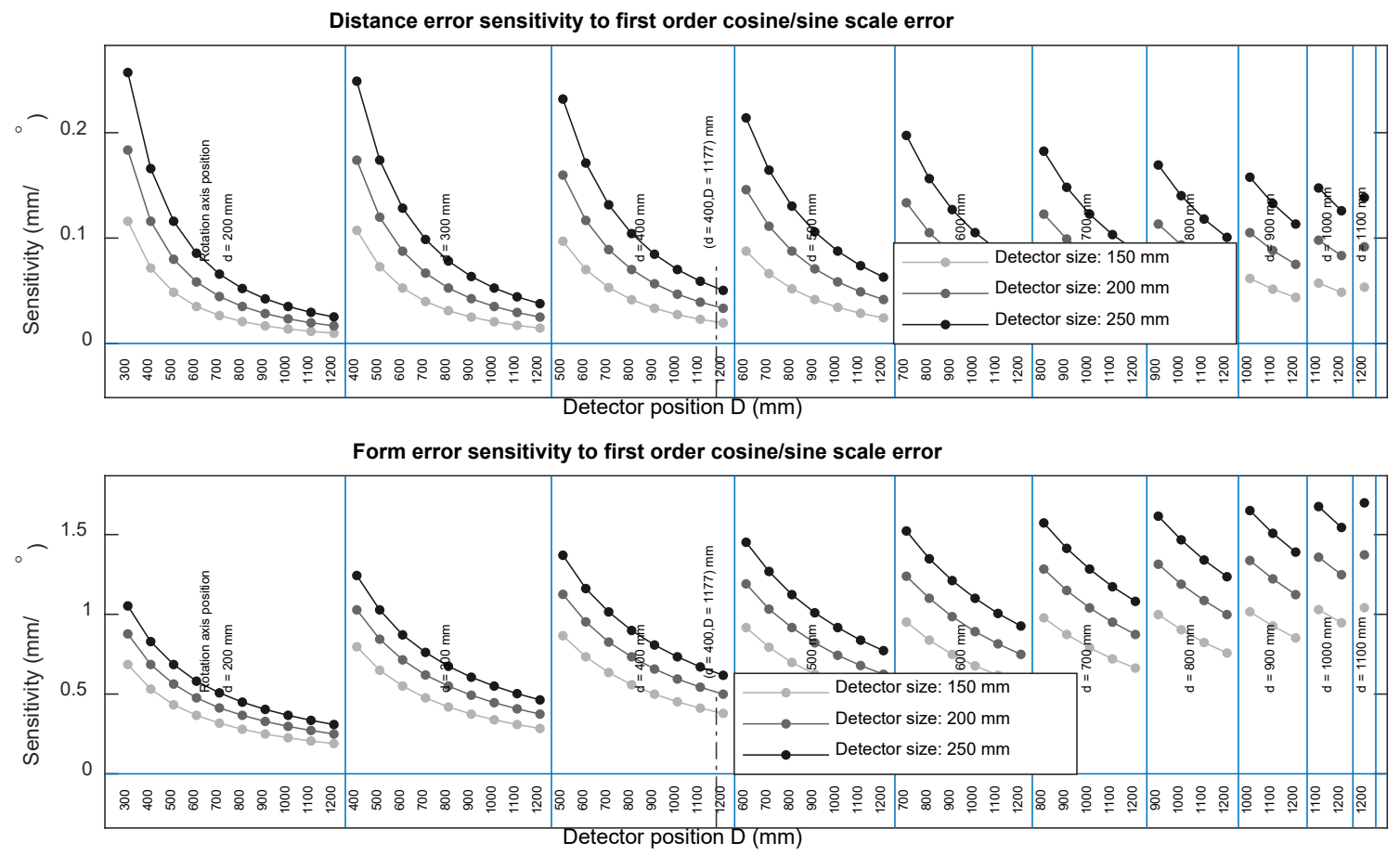

Fig. 29. Distance (top) and form (bottom) error sensitivity to first order cosine and sine scale error.
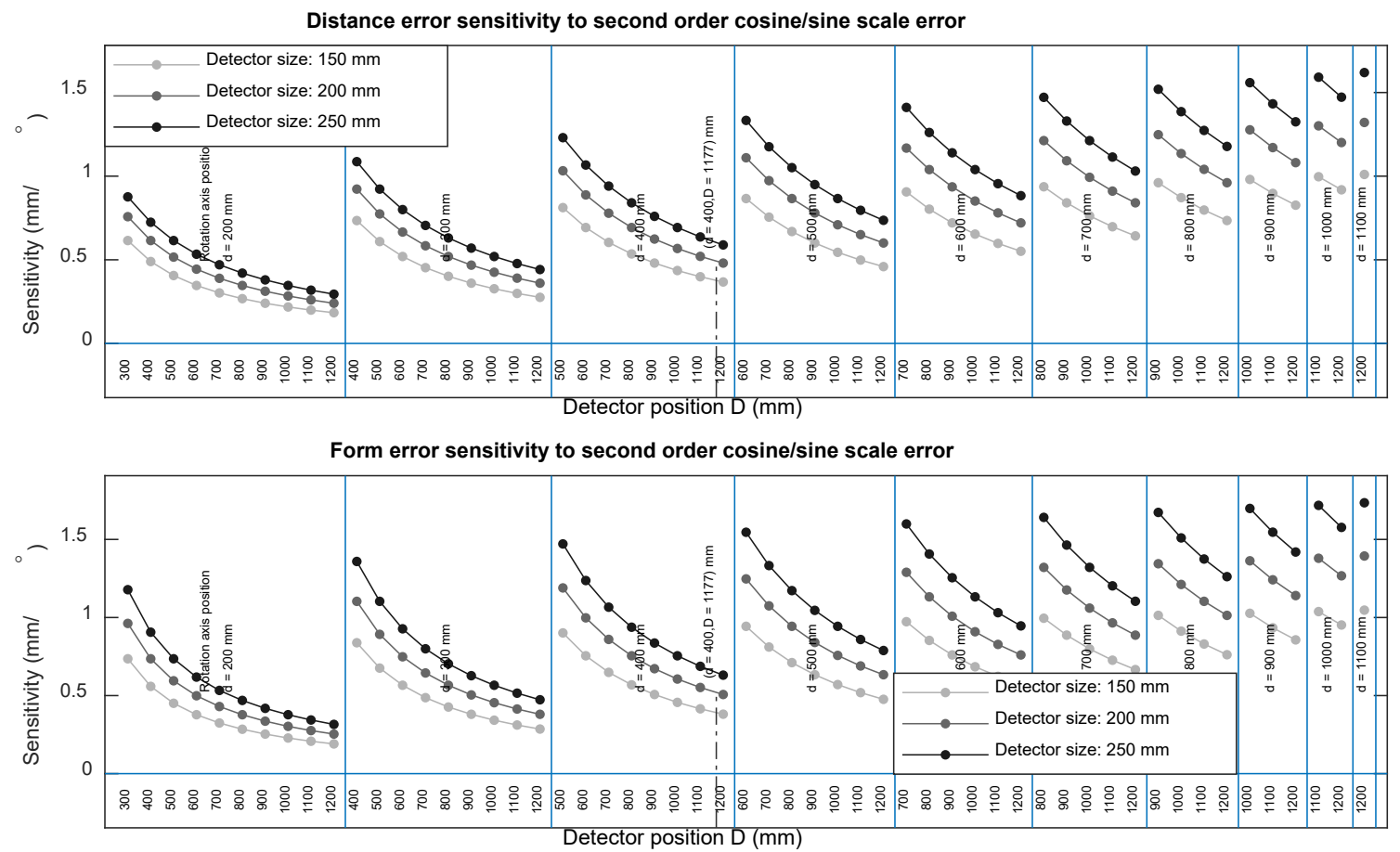

Fig. 30. Distance (top) and form (bottom) error sensitivity to second order cosine and sine scale error. 

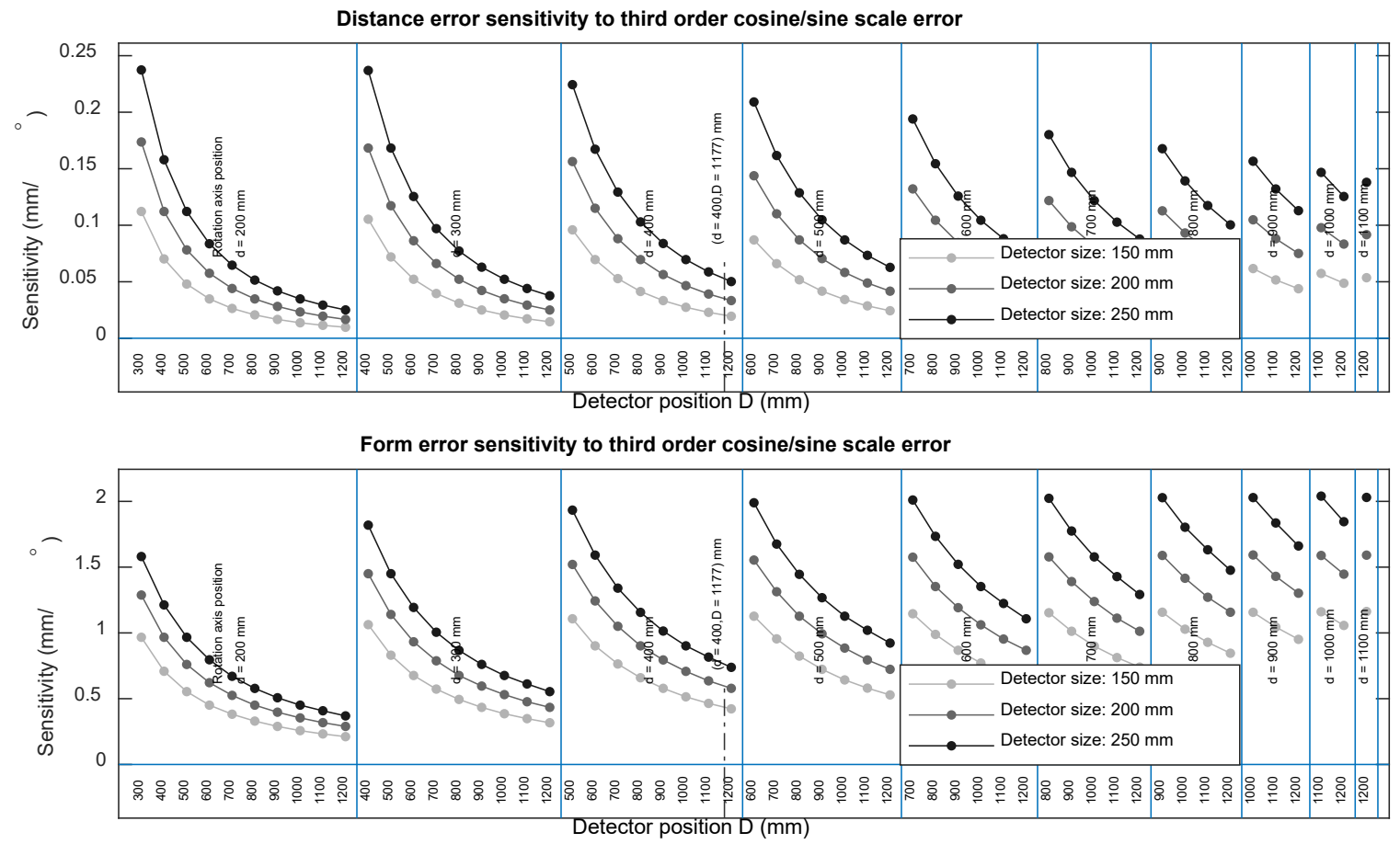

Fig. 31. Distance (top) and form (bottom) error sensitivity to third order cosine and sine scale error.
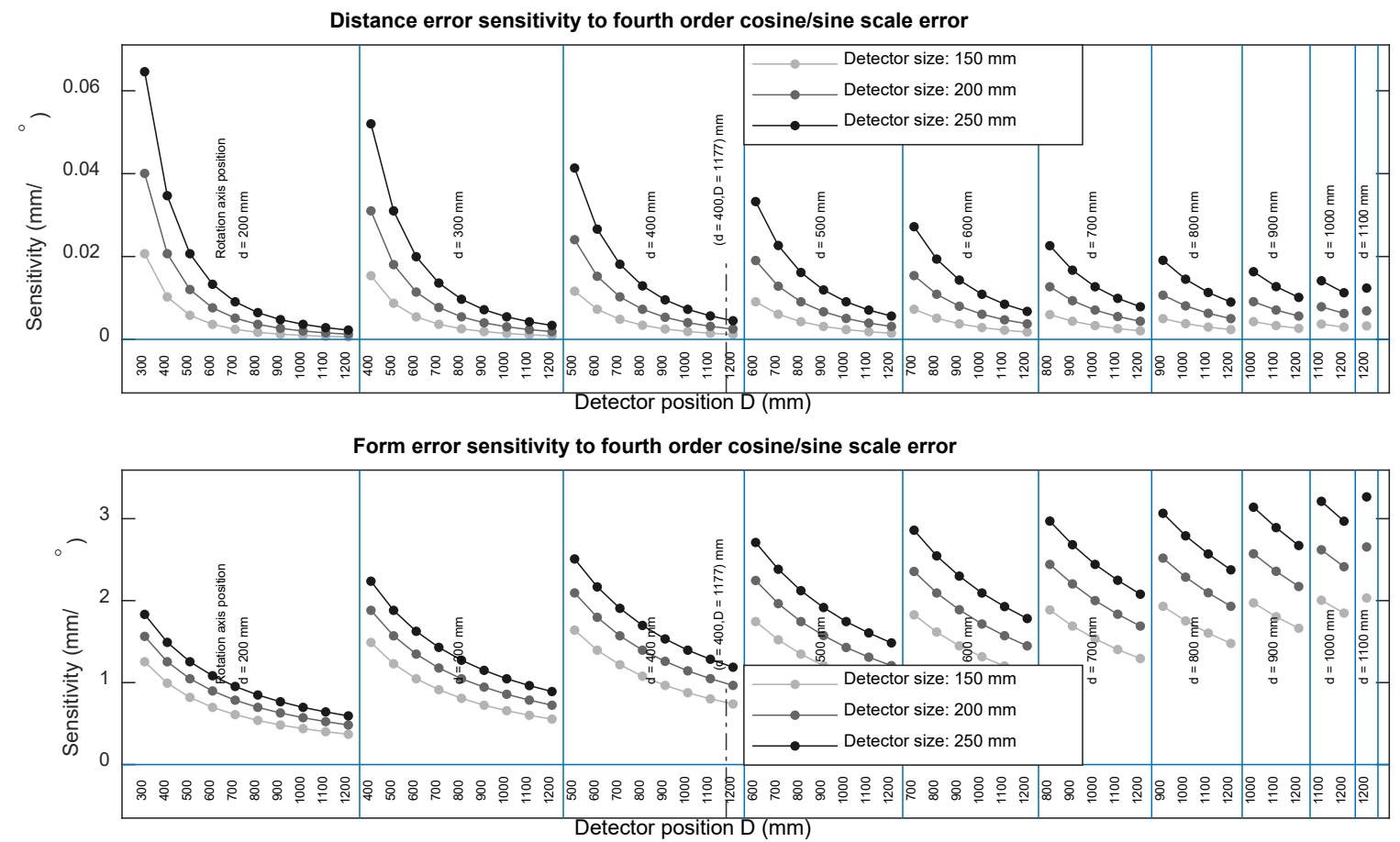

Fig. 32. Distance (top) and form (bottom) error sensitivity to fourth order cosine and sine scale error. 


\section{Summary and conclusions}

In this report, we presented distance and form error sensitivity charts for different XCT instrument geometry errors for different rotation stage distances, detector distances, and detector sizes. The data for these charts were generated as part of a study, the results from which were abstracted and published in Part III [3]. This report presents the underlying data generated from that study; hence, this report may be considered an addendum to the Part III publication. The charts shown in this report can guide users in selecting test positions in their instrument's measurement volume that produce the largest distance and form error for given XCT instrument geometry errors. Some observations from the charts include:

- The 'near' and 'far' positions as mentioned in Secs. 2.4 are optimal locations in the measurement volume for testing purposes as these produce the highest distance and form error sensitivities to the different geometric error sources.

- Some geometric error sources do not result in distance errors, while some do not result in form errors; thus, it is necessary that we test for both distance and form error during the performance evaluation process.

- For a given geometric error source, it is possible that the highest distance error sensitivity might occur at one position (either 'near' or 'far') but the highest form error sensitivity might occur at the other position. Thus, testing at both the 'near' and 'far' positions is advantageous.

- Larger detector sizes result in larger sensitivities to geometric errors. This is because the larger detector area accommodates a larger reference object.

\section{Acknowledgments}

The first author would like to thank Massimiliano Ferrucci for helpful discussions during this work. The authors thank Vincent Lee, Braden Czapla, Felix Kim, and Wei Ren for reviewing the document.

\section{References}

[1] Muralikrishnan B, Shilling M, Phillips S, Ren W, Lee V, Kim F (2019) X-ray computed tomography instrument performance evaluation, Part I: Sensitivity to detector geometry errors. Journal of Research of the National Institute of Standards and Technology 124:124014. https://doi.org/10.6028/jres.124.014

[2] Muralikrishnan B, Shilling M, Phillips S, Ren W, Lee V, Kim F (2019) X-ray computed tomography instrument performance evaluation, Part II: Sensitivity to rotation stage errors. Journal of Research of the National Institute of Standards and Technology 124:124015. https://doi.org/10.6028/jres.124.015

[3] Jaganmohan P, Muralikrishnan B, Shilling M, Morse E (2021) X-ray computed tomography instrument performance evaluation, Part III: Sensitivity to detector geometry and rotation stage errors at different magnifications. Journal of Research of the National Institute of Standards and Technology 126:126029. https://doi.org/10.6028/jres.126.029

[4] American Society of Mechanical Engineers (2020) ASME B89.4.23-X-ray computed tomography $(C T)$ performance evaluation (American Society of Mechanical Engineers, New York). https://www.asme.org/codes-standards/find-codesstandards/b89-4-23-x-ray-computed-tomography-performance-evaluation 
[5] International Organization for Standardization (2021) Draft ISO/DIS 10360-11Geometrical product specifications (GPS) - Acceptance and reverification tests for coordinate measuring systems (CMS) - Part 11: CMSs using the principle of X-ray computed tomography (CT) (International Organization for Standardization, Geneva, Switzerland). https://www.iso.org/standard/73732.html

[6] Ferrucci M, Leach RK, Giusca C, Carmignato S, Dewulf W (2015) Towards geometrical calibration of X-ray computed tomography systems-A review. Measurement Science and Technology 26(9):092003. https://doi.org/10.1088/0957$\underline{0233 / 26 / 9 / 092003}$

[7] Ferrucci M, Ametova E, Carmignato S, Dewulf W (2016) Evaluating the effects of detector angular misalignments on simulated computed tomography data. Precision Engineering 45:230-241. https://doi.org/10.1016/j.precisioneng.2016.03.001

[8] Ferrucci M, Ametova E, Probst G, Craeghs T, Dewulf W (2018) Sensitivity of CT dimensional measurements to rotation stage errors. Proceedings of the 8th Conference on Industrial Computed Tomography (Wels, Austria). 